CUADERNOS DE ESTUDIOS GALLEGOS, LXII Núm. 128 (enero-diciembre 2015), págs. 141-173

ISSN: $0210-847 \mathrm{X}$

DOI: 10.3989/ceg.2015.128.05

\title{
ORACIONES EN PLATA: ESTUDIO DE LA OBRA INÉDITA DE JACOBO PECUL MONTENEGRO*
}

\author{
María CANedo Barreiro \\ Universidad de Santiago de Compostela
}

* El presente artículo deriva del trabajo de fin de máster realizado durante el curso 2013-2014 y dirigido por el Prof. José Manuel López Vázquez, Departamento de Historia del Arte de la Universidad de Santiago de Compostela. 


\section{ORACIONES EN PLATA: ESTUDIO DE LA OBRA INÉDITA DE JACOBO PECUL MONTENEGRO}

\section{RESUMEN}

La presente investigación tiene como objetivo el estudio y atribución de nuevas piezas al orfebre compostelano Jacobo Pecul Montenegro (1753-1817), cuya producción refleja una estética influida por una parte de las formas francesas aprendidas de su padre, Claudio Pecul, y por otra de los artistas gallegos, cómo Ferreiro o Simón Rodríguez.

Se han seleccionado veinticuatro nuevas piezas entre cruces parroquiales, cálices, copones, incensarios, navetas y ostensorios, las cuales aparecen referenciadas en el Libro de Caja de Pecul, extractado por Couselo Bouzas en su Galicia Artística, y catalogadas en el Archivo Diocesano de la Iglesia Católica. Dichas obras han sido estudiadas y atribuidas a Jacobo Pecul siguiendo las directrices marcadas por José Manuel López Vázquez, quién ha tratado en profundidad la obra de este platero.

En estas páginas se realiza un breve análisis del autor así como de las tipologías de orfebrería religiosa del cambio del barroco al neoclásico en Galicia, pretendiendo así mismo ser una llamada de atención sobre la platería gallega, un patrimonio que forma parte de nuestra imaginería popular y que a menudo queda en el olvido.

PalabRAS ClaVE: platería, orfebrería religiosa, cruces parroquiales, cálices, neoclásico, Pecul Montenegro.

\section{ORACIÓNS EN PRATA: ESTUDO DA OBRA INÉDITA DE JACOBO PECUL MONTENEGRO \\ RESUMO}

A presente investigación ten como obxectivo o estudo e atribución de novas pezas ó orfebre compostelán Jacobo Pecul Montenegro (1753-1817), cuxa produción reflexa unha estética influída, por unha parte das formas francesas aprendidas de seu pai, Claudio Pecul, e pola outra dos artistas galegos, como Ferreiro ou Simón Rodríguez.

Seleccionáronse vinte e catro novas pezas entre cruces parroquiais, cálices, copóns, incensarios, navetas e ostensorios, as cales aparecen referenciadas no Libro de Caixa de Pecul, extractado por Couselo Bouzas en Galicia Artística, e catalogadas no Arquivo Diocesano da Igrexa Católica. Ditas obras foron estudiadas e atribuídas a Jacobo Pecul seguindo as directrices marcadas por José Manuel López Vázquez, quen tratou en profundidade a obra deste prateiro.

Nestas páxinas realizase unha breve análise do autor, así como das tipoloxías de ourivería relixiosa no cambio do barroco ó neoclásico en Galicia, pretendendo ó mesmo tempo ser unha chamada de atención sobre a pratería galega, un patrimonio que forma parte da nosa imaxinería popular e que a miúdo permanece esquecida.

Palabras Clave: pratería, ourivería relixiosa, cruces parroquiais, cálices, neoclásico, Pecul Montenegro.

\section{SILVER PRAYERS: A STUDY OF UNKNOWN WORKS BY JACOBO PECUL MONTENEGRO}

Abstract

The purpose of this research is the study and attribution of new pieces to Jacobo Pecul Montenegro (1753-1817) a silversmith from Santiago de Compostela. His production reflects an aesthetic clearly influenced by French forms which he learnt from his father Claudio Pecul. But also Galician artists' work, such as Ferreiro or Simón Rodríguez, had an impact on Montenegro's own creations.

Twenty four new pieces have been selected from parish crosses, holy chalices, ciboriums, censers, "navetas" and monstrances, which are referenced in Pecul's manuscript "Libro de Caja". They were extracted by Couselo Bouzas in his Galicia Artística, and catalogued in the Diocesan Archive of the Catholic Church.

These pieces have been studied and attributed to Jacobo Pecul Montenegro by the guidelines set by José Manuel López Vázquez, who has studied the work of this silversmith in depth.

This article attempts to make a brief study of both the author and the silversmithing typologies in the shift from the baroque style to the neoclassical style. And at the same time this study also aims to draw attention to Galician silversmithing, which is a patrimony of our popular imagery, and more often than not highly neglected.

KEY wORDS: silversmithing, religious silversmithing, parish crosses, holy chalices, neocclasic, Pecul Montenegro. 
Recibido/Received: 03/05/2015

Aceptado/Accepted: 27/07/2015

$\mathrm{L}$

a producción de Jacobo Pecul Montenegro la conforman, dentro del territorio gallego, algunas de las mejores piezas en plata que han llegado a nuestros días, así lo demuestran las obras que se le han atribuido en comparación con otros ejemplos coetáneos.

Sus representaciones son el reflejo del fin de una época muy concreta de la ciudad compostelana, correspondiente al breve periodo de esplendor que se había producido a finales del siglo XVIII; así podemos ver la calidad, suave y elegante, aprendida en el taller de su padre, que bebe de la moda francesa que se había instaurado durante el barroco y de la cual el orfebre es heredero; al mismo tiempo vemos cómo integra formas propias de los escultores o arquitectos gallegos como Ferreiro o Simón Rodríguez, creando un estilo que será distintivo en sus producciones.

En estas líneas se pretende llamar la atención no solo en el trabajo de este gran platero, sino también en el patrimonio orfebre gallego, el cual está constantemente amenazado con desaparecer, debido en gran medida al desconocimiento que se tiene sobre él; resulta incomprensible que, teniendo en cuenta el peso que ha tenido la platería en la ciudad compostelana, los estudios que se pueden encontrar sobre el tema sean tan escasos.

A pesar de que este trabajo se centra solo en la Diócesis de Santiago de Compostela, sabemos que Jacobo Pecul debió de ser un platero respetado en su momento, así parece atestiguarlo el volumen de las piezas de las que tenemos constancia. Para esto es inestimable su Libro de Caja ${ }^{1}$, que es el eje vertebrador de esta investigación. Está escrito por la propia mano del orfebre, pertenecía a don Pablo Pérez Constanti y fue extractado por J. Couselo Bouzas en la voz dedicada a este platero en su Galicia Artística; en él se hacen constar los encargos para 152 parroquias entre los años 1782 y 1817 , este registro demuestra que el platero tenía una importante demanda, tanto de los grandes centros como de parroquias humildes, y que producía para todo el territorio gallego.

\footnotetext{
1 Se recoge en José Couselo BouZAs, Galicia Artística en el siglo XVIII y primer tercio del XIX, Santiago de Compostela, Instituto Teológico Compostelano, 2005 (Collectanea Scientifica Compostellana, 18), págs. 497-509.
} 
Junto a esta fuente de inestimable valor, tenemos los propios objetos litúrgicos, y precisamente, esta es una de las grandes dificultades de su estudio, porque la mayoría de las obras se han perdido. Hay que tener en cuenta que era material de uso diario, que se estropeaba, o se fundía para realizar una nueva pieza más acorde a los gustos del momento o, debido al precio de su material, para cuñar moneda $^{2}$, a lo que hay que añadir los hurtos e incluso las rapiñas y expoliaciones derivadas de las guerras.

\section{Familia Pecul Montenegro}

La familia Pecul se encargó de aportar la última moda ${ }^{3}$ a la platería del barroco en Santiago de Compostela. Fue don Claudio Pecul Montenegro quien encabezó esta dinastía la cual prosiguieron sus tres hijos: Francisco, Jacobo y Luis.

Su trabajo fue muy prolífico y de sus manos vendrá el cambio hacia el neoclásico que se impondrá a finales del siglo XVIII ${ }^{4}$.

Claudio Pecul fue un platero de origen francés, como lo indica la primera documentación que encontramos sobre él en los libros parroquiales de la Corticela, parroquia de extranjeros ${ }^{5}$, donde escribe su nombre como Pecoul y se le llama francés ${ }^{6}$. Desconocemos si se formó con su padre o si fue oficial dentro de los talleres de franceses que lo precedieron en Compostela.

El 15 de Octubre de 1750 contrae matrimonio con Juana de Crespo, con quien tiene ocho hijos: don Cristóbal, don Jacobo, don Luis, don Domingo, don Antonio, doña María Josefa, doña María Ignacia y doña Manuela ${ }^{7}$. Según recoge Murguía, en 1775 regentaba una tienda en la Vía-Sacra, y posteriormente se traslada a la calle de Callobre, a una casa que tenía en propiedad ${ }^{8}$. Sabemos que pertenecía a la congregación de San Eloy -que constituía el gremio de los plateros compostelanos-y que trabajó para la Catedral y también para el Hospital Real; sin embargo conservamos pocas obras suyas en Santiago. Encontramos más piezas en otros lugares, por ejemplo en la Catedral de Mondoñedo, donde se halla un buen número de mobiliario litúrgico de su mano entre vinajeras, platillos, lámparas etc.

\footnotetext{
2 María Dolores Vila Jato, "Orfebrería renacentista en Santiago", en Francisco Singul (ed.), Pratería e Acibeche en Santiago de Compostela. Obxectos litúrxicos e devocionais para o rito sacro e a peregrinación (ss. IX-XX), Santiago de Compostela, Xunta de Galicia, 1998, pág. 159.

3 Rafael Balsa de la Vega, Orfebrería gallega: notas para su historia, Madrid, Fototipia de Hauter y Menets, 1912, pág. 66.

4 Mariel Larriba Leira, "La platería religiosa del Barroco en Compostela" en Francisco Singul (ed.), Pratería e acibeche..., pág. 229.

5 José Couselo Bouzas, Galicia Artística ..., pág. 493.

6 Id. ibid.

7 Id. ibid.

8 Id. ibid.
} 
Al final de su vida, cómo indica don Claudio en su testamento, reside en casa de su hijo Jacobo, quien le da trabajo en su taller y se ocupa de él, hasta su muerte el 16 de Julio de $1796^{9}$.

Tanto su hijo Francisco, el cual se formó en la Academia de San Fernando de Madrid, como Luis, de quien a apenas tenemos noticias, fueron notables plateros, tal y como recoge Murguía ${ }^{10}$.

\section{Jacobo Luis Pecul Montenegro. Apuntes biográficos}

Jacobo Luis Joaquín nace y se bautiza el 17 de Agosto de 1753, en la parroquia de Salomé, teniendo como padrinos a sus tíos, Jacobo de la Piedra, destacado orfebre y grabador compostelano, y su esposa Luisa Crespo (hermana de su madre). Así consta en el Libro $3^{\circ}$ de bautizados, casados y difuntos de Salomé ${ }^{11}$.

Se formó con su padre y trabajó a su lado hasta 1787, cuando establece su propio taller; ese mismo año se casa con la hija menor del escultor Ferreiro, María Manuela, con el que pleiteará a causa de las partijas realizadas en 1812, tras la muerte de la mujer de este, Fermina Gambino, por considerar que su esposa María Manuela salía perjudicada en detrimento de cuñado, Vicente Portela, viudo de su hermana, María Josefa, y que entonces era el principal oficial que trabajaba en el taller de su suegro y maestro. Será un largo conflicto que provocará que Ferreiro abandone definitivamente Santiago; los pleitos continuarán entre Portela y Pecul y nunca llegarán a buen término, cerrándose estos con la muerte de Jacobo Pecul en $1817^{12}$.

En 1792 recoge de su padre el cargo de platero del Real Hospital y en 1805, por la Suprema Junta de Comercio y Moneda, se le concede el título de "Ensayador de metales en España y Fiel contraste mercader de plata y tocador de oro en Santiago y su jurisdicción"13. A pesar de que conservamos obras suyas a lo largo de toda Galicia, Couselo Bouzas da a entender que nunca salió de Santiago de Compostela ${ }^{14}$.

A la hora de firmar utiliza los dos apellidos de su padre: Pecul Montenegro. Él mismo, como había hecho su progenitor, instauró una escuela que se continuaría

\footnotetext{
9 José Couselo Bouzas, Galicia Artística ..., pág. 494.

${ }^{10}$ Id. ibid., pág. 510.

${ }^{11}$ Fermín Bouza Brey, "De la fecha de nacimiento y otros datos del orfebre compostelano Francisco Pecul”, Compostellanum, vol. 9, nº. 2 (1964), págs. 307-308.

12 José Manuel López VÁzQuez, "La escultura neoclásica", en Francisco Rodríguez Iglesias (dir.), Galicia. Arte, v. XV, A Coruña, Hércules Ediciones, [d. 1. 1993], págs. 90-92.

13 José Couselo Bouzas, Galicia Artística..., pág. 498.

14 Id. ibid.
} 
hasta la primera mitad del siglo XIX ${ }^{15}$; de esta saldrán orfebres notables cómo Andrés de Senra (1788) o su primo Antonio Piedra, entre otros ${ }^{16}$.

López Vázquez es quien más ha tratado su obra, estableciendo una tipología y una cronología, las cuales son indispensables para llevar a cabo la tarea de atribución que se realiza en este proyecto. Asímismo se realizará un breve comentario de las obras ya conocidas de Pecul siguiendo especialmente sus publicaciones, como Juegos de plateros Compostelanos (1787-1914), Tipoloxías da ourivería o Tipologías de la orfebrería religiosa gallega, donde aparece referenciada la mayor parte de la obra de este platero $^{17}$.

\section{Evolución tiPolóGicA HaCia el NeOclásico y ESTUdio de LA OBRA DE JACOBO PECUL}

Para entender la evolución hacia al neoclásico en la orfebrería compostelana hay que tener en cuenta los talleres de extranjeros, los cuales eran muy habituales, tanto que se crearon unas duras medidas proteccionistas en 1746 para favorecer a los talleres locales ${ }^{18}$, sin embargo, los obradores franceses promovían una nueva estética que cada vez despertaba más interés, por ello las ordenanzas realizadas en 1786 ya son más laxas, alentando la asimilación de nuevas formas y diseños ${ }^{19}$, con un cariz más delicado de lo que era habitual en los talleres de Santiago.

En un primer momento los orfebres se opusieron a esta nueva estética francesa, pero había que contar con que en Santiago en esta época se encontraba un buen número de artífices galos que se sentían cómodos con esta nueva moda, y es ahora

\footnotetext{
${ }^{15}$ Santiago Alcolea Gil, Artes decorativas en la España cristiana: siglos XI-XIX, vol. 20, Ars Hispaniae, Madrid, Plus Ultra, 1975, pág. 242.

${ }^{16}$ José Couselo Bouzas, Galicia Artística..., pág. 508.

${ }^{17}$ A través de la evolución tipológica y las atribuciones que ha realizado del autor se ha podido llevar a cabo este proyecto, los manuales claves para ello son: José Manuel López VÁzquez, "Tipologías de la orfebrería religiosa gallega", en Rafael Taboada Vázquez (dir.), Oro, plata y piedra para la escena sagrada en Galicia: curso de orfebrería y arquitectura religiosa: La Coruña, del 2 al 11 de Mayo de 1994, A Coruña, Asociación de Amigos de la Colegiata y del Museo de arte Sacro de La Coruña, 1995, págs. 91-127; "Tipoloxías da ourivería”, en José Manuel García Iglesias, Galicia Renace: exposición en Santiago de Compostela en la iglesia de San Martín Pinario: 10 de xuño-outubro, Consellería de Cultura e Comunicación Social, [d.1. 1997]; y "Juegos de Plateros compostelanos en el arte contemporáneo (1787-1914)", en Francisco Singul (ed.), Pratería e Acibeche en Santiago de Compostela. Obxectos litúrxicos e devocionais para o rito sacro e a peregrinación (ss. IX-XX), Santiago de Compostela, Xunta de Galicia, 1998, págs. 347-360.

${ }^{18}$ Yolanda Barriocanal López, "Las ordenanzas de los plateros compostelanos del año 1786", $M i$ nius: revista del Departamento de Historia, Arte e Xeografia, 2-3 (1993/94), pág. 150.

${ }^{19}$ Francisco Singul, "La platería y el Azabache compostelanos: una reflexión previa al estudio de sus tipologías, formas y tradiciones", en Francisco Singul (ed.), Pratería e Acibeche..., pág. 27.
} 
cuando la familia Pecul entra en acción ${ }^{20}$, mostrando un tono más elegante y fino, pero que se irá perdiendo paulatinamente.

Pecul Montenegro es una figura clave dentro de la platería compostelana, pues será el orfebre más exitoso del tránsito del s. XVIII al XIX, personifica por tanto el cambio del Barroco al neoclásico, abriendo nuevas vías tanto estructurales como decorativas, que no solo van a ser las que más triunfen y se imiten en el siglo siguiente, sino que además serán las que formalicen y establezcan las formas del neoclásico.

Pecul conforma su nuevo estilo promoviendo innovaciones basadas en eliminar los elementos más aparatosos, como la rocalla, y simplificando las formas. Para esto se va a ayudar, probablemente, del estilo aprendido en el taller de su padre, de gusto francés, más refinado, así recoge las formas barrocas y las dota de mayor elegancia y esbeltez, las cuales irá perfeccionando a lo largo de su producción.

Además, se dejará influir, como hemos indicado, por los artistas compostelanos, como Ferreiro, su suegro, o el arquitecto Simón Rodríguez, del cual tomará el motivo de óvalos en resalte, que será característico de su producción.

Todo ello da como resultado las piezas más originales e innovadoras del cambio de siglo, que establecerán la pauta a seguir de las demás piezas de orfebrería neoclásicas.

\section{Cruces parroquiales ${ }^{21}$}

Desde el Concilio de Santiago, en el cual el Obispo Cresconio dicta que todas las parroquias gallegas deben tener una cruz parroquial, estas van a ser el emblema de cada parroquia. Por ello los distintos territorios van a competir entre sí para tener la mejor cruz, y a poder ser de plata ${ }^{22}$. Cómo expresa López Vázquez en Tipologías de la orfebrería religiosa gallega, la cruz parroquial se convierte en un símbolo de los feligreses capaz de crear una conciencia de comunidad diferenciada ${ }^{23}$.

Existen cruces de bronce, pero lo normal es que las cruces sean de plata en su color, aunque también es habitual que los motivos principales aparezcan sobredorados y en alguna ocasión se sobredora la pieza en su totalidad ${ }^{24}$. La estructura de

\footnotetext{
${ }^{20}$ Rafael Balsa de la Vega, Orfebrería gallega... pág. 65.

${ }^{21}$ La cruz parroquial se compone de diversas partes; un engarce o vástago que sirve de unión con el mástil o vara, en la cual se levantará; una macolla (también denominada manzana o nudo) cuya forma sufrirá grandes transformaciones con el paso de los diferentes estilos. El punto de unión de los brazos de la cruz se conoce cómo cuadrón y puede aparecer en forma circular o cuadrada.

22 José Manuel López VÁzQuez, “Tipologías de la orfebrería...”, pág. 92.

23 Id. ibid., pág. 91.

${ }^{24}$ Id. ibid., pág. 95.
} 
las cruces parroquiales gallegas se regulariza en el siglo XVI: cruz griega, cuadrón cuadrado, brazos flordelisados o trilobulados, resaltes figurados con tetramorfos y macolla muy desarrollada, sobre la cual era común representar un apostolado ${ }^{25}$.

A medida que avanza el barroco se van perdiendo las reminiscencias góticas derivando hacia formas más simétricas y bulbosas. El tipo de Cristo, representado siempre en el anverso del cuadrón, irá evolucionando siguiendo las pautas que podemos encontrar en la escultura; lo normal es que en el reverso se sitúe el santo titular ${ }^{26}$.

Durante los últimos años del siglo XVIII el estilo Barroco va derivando hacia el neoclásico, lo que supone la simplificación del remate de los brazos, con formas trilobuladas, abandonando la forma enmarcada por dos "eses" contrapuestos que había sido lo habitual, y se impone la cruz latina ${ }^{27}$.

Con respeto a las cruces realizadas por Pecul, van a ser como anunciamos, las que traigan nuevas formas. Estas innovaciones, que marcan la nueva moda, las explica López Vázquez en su artículo Tipoloxías da ourivería, y se pueden sintetizar en: simplificación en el remate de los brazos, una decoración que se libera de los elementos recargados típicos del barroco, como pueden ser las vieiras y cartelas con rocalla, cambiándolas por una ornamentación más simple: óvalos lisos, con o sin relieve; además introduce la retícula de rombos sobre la superficie de la cruz $^{28}$.

También será de suma importancia la supresión del cuadrón, acentuando así la forma de cruz. El otro elemento decorativo clave en el estilo de Pecul, serán los rectángulos en resalte, cuyos lados cortos se curvan hacia dentro para acoger una roseta o un pequeño óvalo ${ }^{29}$.

En lo que se refiere a las macollas, a pesar de que mantiene la forma periforme, en sus obras más originales las divide en tres partes por medio de resaltos, decorados con cabezas de querubines y se ornamenta con ristras de flores ${ }^{30}$.

En las primeras, documentadas en los años 70 del siglo XVIII, aun mantienen el cuadrón circular del que parten rayos, una macolla periforme y un crucificado con el paño anudado delante que cae a ambos lados. Lo más novedoso es la decoración que ya introduce una retícula repujada que parte del cuadrón, la acompaña

\footnotetext{
${ }^{25}$ Rosa VÁzquez Santos, "Pratería Compostelá barroca e neoclásica. Cruces procesionais, cálices e ostensorios", en Calvo Domínguez, Marcelina (dir.), Santiago. A Esperanza, Xunta de Galicia, [d. 1. 1999], pág. 548.

26 Id. ibid.

${ }^{27}$ Rosa VÁzquez Santos, "Pratería Compostelá barroca...”, pág. 552.

28 José Manuel López VÁzquez, “Tipoloxías...”, pág. 265.

29 Id. ibid.

30 Id. ibid.
} 
con el motivo de óvalos enmarcados en otros circulares, que recoge de Simón Rodríguez; como remate coloca una venera convexa ${ }^{31}$. Ejemplos de este momento son las cruces de Santa María de Sésamo (1778) y San Breixo de Sergude (1780).

En los años 80 ya suprime el cuadrón, de este modo en el anverso la cabeza del crucificado se coloca sobre un sol, cuyos rayos se prolongan por haces en los ángulos de los brazos de la cruz. La decoración de retícula se simplifica por una red de puntos y en los extremos de los brazos sitúa una flor y una rocalla simple. La macolla es periforme, dividida en tres zonas unidas a la cruz y al astil a través de boceles agallonados. Estas características se reflejan en la cruz de San Xoán de Lousame $(1789)^{32}$.

En los años 90 encontramos las dos cruces claves para las nuevas formas introducidas por Pecul, la cruz de San Xoán de Touro (1796) y la Cruz de Santo Domingo de Bonaval, que a pesar de ser dos años anterior será la que inaugure el tipo más utilizado en Galicia hasta finales de los años 20 del siglo XIX ${ }^{33}$.

En San Xoán de Touro, mantiene la retícula, pero ahora la realiza a base de escamas y da más antención a la decoración de óvalos ${ }^{34}$.

En Santo Domingo de Bonaval adopta ya el modelo de cruz latina, brazos trilobulados en su remate y decoración geométrica que puede cobijar rosetas. La macolla sigue siendo periforme invertida, pero ahora se cuartela mediante molduras en relieve donde se colocan cabezas de querubines. La unión al vástago mantiene el bocel agallonado, y la cruz se une con una pieza independiente, trapezoidal y ornamentada. El crucificado proviene de un nuevo molde, que se utilizará durante la primera mitad del siglo XIX, imitándose incluso en las obras en madera: Cristo ladea la cabeza hacia la derecha y hacia atrás, mientras que el cuerpo describe una suave curva, el paño de pureza se sujeta con una cuerda que deja al descubierto la cadera y la pierna derecha, cintada volante y fruncida en la parte central.

Esta forma se inspira en una obra napolitana del siglo XVII, que se conserva en la academia madrileña de San Fernando. En esta cruz además va a aparecer la decoración de los brazos compuesta por dos rectángulos en resalto, con los lados cortos curvos para acoger o bien rosetas o bien pequeños óvalos, que será el tipo de ornamentación más exitoso ${ }^{35}$.

Este modelo será el más repetido a lo largo del siglo XIX y lo podemos ver en otros ejemplos como en la de la Colegiata de A Coruña (1796), San Estevo

\footnotetext{
${ }^{31}$ José Manuel LóPez VÁzquez, “Juegos de Plateros compostelanos...”, pág. 347-348.

${ }^{32}$ Id. ibíd., pág. 348.

33 José Manuel López VÁzquez, “Tipoloxías...”, pág. 265.

${ }^{34}$ Id. ibid.

${ }^{35}$ Id. ibid.
} 
de Paradela (1803), San Tirso de Mabegondo (1799), Santa María de Gándara (1801), San Cristobo de Eixo (1807), San Vicente de Cespón (1813), San Cristobo de Abanqueiro (1814), San Pedro de Borrifáns (1815) y en la de San Xulián de Brantuas $^{36}$.

Existe, además un molde de Crucificado diferente a los dos anteriores, que podemos ver en las cruces de Santa María de Ledoira (1797), Santa María de Turces (1799), Santa Baia de Abegondo (1799), Santa María de Leira (1801), Santa María de Alba (1802) o Santa María de Órdenes. Este Cristo nos remite al primero, pero se diferencia en el paño de pureza, relacionado con el que se producía en el taller de Ferreiro, un paño pequeño que se ajusta a la pelvis, anudado en la cadera derecha ${ }^{37}$.

\section{Cálices $^{38}$}

A pesar de que las partes fundamentales del cáliz no variarán, en el transcurso del siglo XVII se suprime prácticamente toda la decoración, aunque junto con estos modelos tan sobrios y desornamentados coexisten tipos de cálices muy decorados, especialmente durante el rococó ${ }^{39}$.

En cuanto la evolución hacia el neoclásico también será Pecul quien dé el paso decisivo. Durante la segunda década del siglo XVIII se había puesto de moda un tipo de nudo en el astil del cáliz que se componía por dos elementos, uno ovoide y un toro, que comenzaron a fusionarse dando lugar a un nudo periforme dividido por boceles, este nudo se mantendrá hasta la década de los 80 con leves modificaciones ${ }^{40}$.

López Vázquez en Tipoloxías da oruivería, detalla como Pecul, desde este modelo formaliza el tipo que triunfará en el neoclásico, lo vemos en el cáliz de San Xoan de Camboño, donde suprime la división de boceles ofreciendo un aspecto, ahora sí, verdaderamente periforme, el cual irá ganando en esbeltez y elegancia con el paso del tiempo ${ }^{41}$. Este será uno de los primeros cálices que conservamos del orfebre, es liso, con un pie circular formado por una pestaña y una moldura en talud, sobre la que se dispone otra sinuosa que se funde, un toro con un tronco de cono. El astil tiene un primer tramo simétrico, lo sigue el nudo

\footnotetext{
36 José Manuel López VÁzquez, “Juegos de Plateros compostelanos...”, pág. 349.

37 Id. ibid.

${ }^{38}$ Los cálices se conforman por varias partes: un pié o basamento, un astil o vástago, que es la zona por donde se agarra, y la copa, que puede estar dividida por una fina moldura denominada plato; si esto ocurre podemos hablar de una subcopa.

39 Rosa VÁzquez Santos, "Pratería Compostelá barroca...”, pág. 554.

40 José Manuel López VÁzquez, “Tipoloxías...”, pág. 268.

${ }^{41}$ Id. ibid., pág. 269
} 
periforme invertido y se remata con un copa campaniforme divida por un plato ${ }^{42}$.

En los cálices posteriores no encontraremos cambios sustanciales en la molduración o en la configuración, pero si serán piezas más altas y esbeltas, sobre todo en la base, por ejemplo San Pedro de Borrifáns $(1815)^{43}$ o en el de San Paio de Carreira (1814), donde se elimina el juego de concavidades que presentaban los dos anteriores en la base, a través de una moldura de borde en el talud ${ }^{44}$.

Los cálices que marcan una verdadera diferencia son los que se decoran, por ejemplo el de Santa Baia de Camba, con cartelas, los elementos de la Pasión y guirnaldas de rosas ${ }^{45}$; pero especialmente el de la Colegiata de A Coruña ${ }^{46}(1805)$, el cual ha sido estudiado por Louzao Martínez. En su estructura no se encuentran grandes cambios con respecto a los anteriores, pero son mucho más suntuosos, se doran y añaden elementos como rosarios de perlas, motivos de la Pasión y múltiples guirnaldas de flores y formas vegetales.

\section{Copones $^{47}$}

Hay que entender la evolución de los copones muy cercana a la de los cálices, por lo menos en lo que se refiere a la molduración del astil, serán piezas de gran sobriedad en su configuración y prácticamente no tendrán ornamentación.

Entre los copones de Pecul se encuentran pocas diferencias, y entre ellos el Copón de Santa María de Vilachá (1811) o el de San Lorenzo de Olas, puede servir como ejemplos para conocer su estilo.

El astil comienza superponiendo varios boceles, creando un cuello sobre el que se dispone un nudo periforme invertido, se remata con dos cuellos, de los cuales el superior es más largo, separados por un bocel. La copa, semiesférica y lisa, repite el mismo juego de curvas que la base y se remata por una cruz radial ${ }^{48}$. Este tipo sufrirá pocas modificaciones comparado con los demás ejemplos de Pecul a lo largo de su producción.

En el copón de Santa María de Leira el astil se conforma de forma diferente, arrancado de un medio bocel y un cuello y rematándose en otro largo cuello tras

\footnotetext{
${ }^{42}$ Id. ibid.

${ }^{43}$ José Manuel López VÁzquez, "Juegos de Plateros compostelanos...”, pág. 350.

${ }^{44}$ Id. ibid.

${ }^{45}$ Id. ibid.

${ }^{46}$ Id. ibíd. Datados por Louzao Martínez en 1805.

${ }^{47}$ Los copones se componen de un pie que suele aparecer sin decoración, un astil, una copa semiesférica lisa y una tapa también simple, que suele reproducir el juego sinuoso de la base y que se remata de una cruz.

48 José Manuel López VÁzquez, “Juegos de Plateros compostelanos...”, pág. 352.
} 
el nudo ${ }^{49}$. En el copón de Santa María de Argalo, se diferencia del anterior en que el nudo periforme se estrangula ligeramente en su centro ${ }^{50}$.

De nuevo destaca por su ornamentación, el Copón de la Colegiata de A Coruña, en la tapa coloca una representación del Agnus Dei que descansa sobre el libro de los siete sellos ${ }^{51}$. El astil se decora con motivos eucarísticos, como los sarmientos y las hojas de vid, que envuelven el vástago y parecen sostener la copa. La base también se decora con vegetación, perlas y en una de las caras un dibujo geométrico grabado, finalizando con el borde en talud y una pestaña ${ }^{52}$. De este estilo también se conserva el copón de la Capilla de los Dolores de Ferrol $(1793)^{53}$.

\section{Incensarios $^{54}$}

Los incensarios evolucionarán significativamente desde el Renacimiento, sin embargo en el barroco no se poducirá una evolución formal ${ }^{55}$; será la forma que adquiere el cuerpo del humo y la decoración lo que indique su cronología.

Los ejemplos más tempranos tienen un cuerpo menos desarrollado en altura y más redondeado, a medida que se avanza en el tiempo el incensario se alarga y decora. Se utilizarán nervios para dividir el cuerpo, se calan mucho las diferentes zonas y se recurre a remates mixtilíneos y a decoración de rocalla ${ }^{56}$.

López Vázquez establece dos tipos dentro de los incensarios conocidos de Pecul. El primero cuenta con ejemplos como el de Santa María de Alba o Santa María de Castelo, presentan un cuerpo de humo periforme, muy calado y casi esférico ${ }^{57}$.

Se puede dividir estructuralmente en tres partes. La inferior presenta una moldura en talud lisa, que ejerce la función de tapa y la central se subdivide verticalmente en tres cuarteles, cubriendo los nervios con hojas de acanto. En los cuarteles coloca decoración de "ces", veneras, flores o palmas, que enmarcan diferentes motivos según el ejemplo, (vanos trapezoidales en el de Alba o espejos en el de Castelo). El cierre redondeado está calado ornamentado con hojas de

\footnotetext{
49 Id. ibid.

50 Id. ibid.

${ }^{51}$ De los que se han perdido tres. José Manuel López VÁzquez, “Juegos de Plateros compostelanos...”, pág. 354.

52 Id. ibid.

53 Id. ibid.

${ }^{54} \mathrm{Se}$ forman por una base o pie, una casca que se cierra con el cuerpo principal o cuerpo del humo el cual aparece horadado, y que se une por medio de una cadena a un manípulo.

${ }^{55}$ Mariel Larriba LeIra, "La platería religiosa...”, pág. 238.

56 José Manuel López VÁzquez, “Juegos de Plateros compostelanos...”, pág. 356.

${ }^{57}$ Id. ibid., págs. 356-357.
} 
acanto unidas en un anillo liso donde se colca el cierre esférico, las hojas se juntan en el centro donde se coloca una argolla para la cadena. La casca es periforme invertida, dividida en cuarteles con hojas de acanto y ramilletes de flores. El pie es muy simple, formado por una pestaña, un cuarto de bocel y un cuello bajo que lo une con la casca ${ }^{58}$.

El segundo tipo está representado en el incensario de San Estevo de Paradela, las diferencias entre ellos no son muchas. El cuerpo del humo es ahora plenamente periforme, y las cartelas presentan un marco doble, disminuyendo la zona de decoración y el calado. Se modifica la base formándose con una moldura en borde de talud, un toro plano y un cuello ligeramente más largo que el del primer tipo ${ }^{59}$.

\section{Navetas $^{60}$}

Poco, por no decir nada, se ha interesado la bibliografía por tratar la evolución tipológica de las navetas, que tienen como función guardar el incienso. López Vázquez ha datado cómo la naveta más antigua conocida de Pecul la de Santiago de Arzúa (1792), con ella se puede comenzar a pautar el estilo que va a seguir el orfebre a lo largo de su producción ${ }^{61}$.

Tiene forma de nave, con quilla elíptica, decorada con relieves vegetales. En esta primera pieza ya podemos ver el doble listel con el que se separa el campo ornamental del mascarón, esto va a repetirse no solo en las obras de Pecul, sino también en la producción de los plateros de Santiago durante el siglo XIX ${ }^{62}$.

Aunque en este primer ejemplo se pueden ver muchas de las características de su estilo, López Vázquez presenta como reguladora del diseño la naveta de Santa María de $\mathrm{Alba}^{63}$. La parte superior se enmarca en su totalidad con un listel en relieve y el paso del mascarón a la quilla solo se contrasta por la ornamentación, que es completamente diferente; en la quilla continúa con la decoración a base de rosas y el mascarón se cubre con una gran vieira. Lo más característico que marca un cambio evolutivo vuelve a ser la esbeltez, en esta pieza se ve sobre todo en el basamento, compuesto por una moldura en talud y otra troncocónica sinuosa. El pie también aparece profusamente decorado con hojas de acanto repujadas.

\footnotetext{
${ }^{58}$ Id. ibid.

${ }^{59}$ Id ibid.

${ }^{60} \mathrm{Se}$ componen de un pie, que suele recibir decoración vegetal y un cuerpo en forma de nave, que suele crecer formando un mascarón curvo; esta zona también se suele ornamentar con elementos vegetales y estriados, imitando veneras. El cuerpo se cierra con una tapa plana que normalmente se completa con un tirador.

61 José Manuel López VÁzquez, “Juegos de Plateros compostelanos...”, pág. 357.

62 Id. ibid.

63 Id. ibid.
} 
Desde este modelo los cambios que podemos apreciar con otros ejemplos, como la naveta de Cristobo de Abanqueiro o San Estevo de Piadela son mínimas, responden a pequeñas diferencias en cuánto esbeltez y ornamentación, pero que no suponen un cambio en el modelo implantado por Santa María de Alba ${ }^{64}$.

\section{Ostensorios $^{65}$}

De nuevo la evolución puede marcarse a través de la estilización de formas. Lo más singular es el viril, que normalmente adoptará el tipo "sol", que es el más extendido y que se caracteriza por su forma circular, que es habitual decorar con nubes desde las que pueden asomar cabezas de ángeles alados y de las que parten rayos.

El gran cambio en las custodias se dará ya a inicios del siglo XIX, cuando se romperá con todos los tipos dados hasta el momento ${ }^{66}$. Los pies ganarán movimiento con formas onduladas, donde se pueden representar escenas bíblicas, y en algunas custodias se pueden observar piezas exentas o recortes. Hay ejemplos en los que el astil se convierte en un ángel que sujeta el viril decorado aún con el motivo de nubes, sobre las que se colocan ramos de vid y de la que parten rayos ${ }^{67}$.

Una vía alternativa en este primer tercio del siglo XIX es la seguida por Antonio Reboredo, por ejemplo la custodia ostensorio de Santa María do Camiño. Es el equivalente al estilo "fernandino": pie circular, astil con nudo fernandino y decoración de "ces", hojas y perlas ${ }^{68}$.

Dentro de la producción de Pecul los motivos que adornan el viril son tres: nubes, soga de perlas y los rayos que rodean el sol. La base de los ostensorios mantienen el formato típico del orfebre compostelano, similar al de los cálices: circular, compuestos de una pestaña seguida de una moldura en talud y sobre ella otra moldura sinuosa.

El tipo más sencillo es el de el Salvador de la $\mathrm{O}$, la base responde a la forma propia de Pecul: el astil se compone de un cuarto de bocel, un cuello y un balaustre. El sol se adorna con un círculo de nubes muy fino de la que salen rayos que alternan longitud ${ }^{69}$. El ostensorio de Santa María de Tronceda es muy similar al anterior, pero el astil gana en molduración, y en lugar del motivo de nubes utiliza las perlas ${ }^{70}$.

${ }^{64}$ Id. ibid., pág. 358.

${ }^{65}$ Se dividen principalmente en tres partes: base, astil y viril.

${ }^{66}$ Rosa Vázquez Santos, "Pratería Compostelá...”, pág. 556.

${ }^{67}$ Id. ibid.

${ }^{68}$ Id. ibid.

${ }^{69}$ José Manuel LóPez VÁzQuez, “Juegos de Plateros compostelanos...”, pág. 354.

${ }^{70}$ Id. ibid. 
Hay piezas que no varían su estructura básica, distinguiéndose solo por una ornamentación más suntuosa. En el de San Tirso de Mabegondo (1798), se mantiene el típico pie de Pecul, pero decorado con palmetas y dividido en cartelas con motivos eucarísticos. A lo largo del astil hay sartas de flores repujadas y cabezas de querubines ${ }^{71}$.

Cómo en los casos anteriores destaca el realizado para la Colegiata de A Coruña, estudiado por Louzao Martínez: viril rodeado por nubes que se encierra por una guirnalda con flores y pedrería, del que parten rayos y se corona por una cruz lobulada, también se decora con ramos de vid de alusión eucarística. Como astil coloca la figura de un angelito que porta en una mano unas espigas y en la otra los sarmientos del sol. El pie posee cierta forma ovalada y en él coloca escenas bíblicas ${ }^{72}$.

\section{CATAlogación DE LA OBRA INÉDITA}

Una vez estudiada la tipología y evolución de la producción de Jacobo Pecul, pasamos a la catalogación de su obra inédita. Todas las piezas seleccionadas aparecen referenciadas en el Libro de Caja del platero y se han contrastado con las fichas de catalogación documentadas en el Inventiario de Bienes Muebles de la Iglesia Católica, consultado en el Archivo Histórico Diocesano de Santiago de Compostela, así como con las formas establecidas por López Vázquez cómo reguladoras del estilo de Pecul. Se propone la atribución de veinticuatro nuevas piezas: ocho cruces, cinco cálices (tres lisos y dos ornamentados), cuatro copones lisos, tres incensarios, dos navetas y dos ostensorios.

\section{Cruces parroquiales}

La mayor parte de las cruces que se atribuyen en estas lineas a Jacobo Pecul se pueden agrupar en dos tipos, ya documentados por López Váquez ${ }^{73}$, por un lado las cruces que siguen las pautas del modelo de Santo Domingo de Bonaval (1794) y por otro las que imitan al de San Xoan de Lousame (1789).

Las seis primeras siguen el modelo de Santo Domingo de Bonaval: constan de brazos en remate trilobular, en cuyo centro se sitúa un pequeño óvalo en relieve; a lo largo de los brazos la superficie corre lisa y cómo ornamentación se colocan rectángulos en resalte, decorados con una red de rombos en los cuales se puntean los ángulos, dando la apariencia de una especie de flor; se alternan unos más largos

\footnotetext{
${ }^{71}$ Id. ibid.

${ }^{72}$ Id. ibíd., pág. 355.

${ }^{73}$ Id. ibid., págs. 347-349.
} 


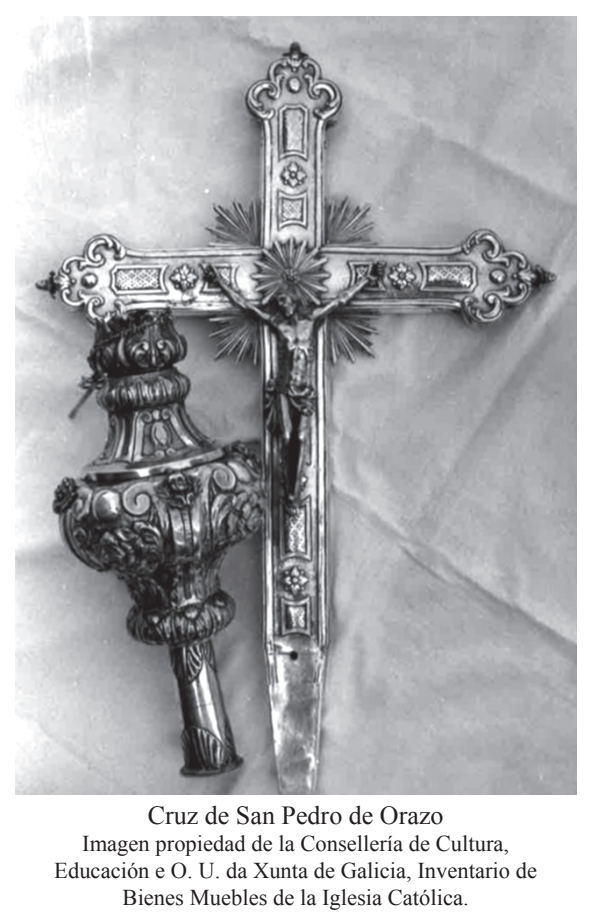

con otros más pequeños, con los lados cortos curvos para cobijar entre ellos una roseta.

El molde del Cristo es siempre el mismo, su cuerpo adopta una ligera curvatura, la cabeza se ladea a la derecha y se reclina hacia atrás. El paño de pureza se sujeta por una cuerda y deja al descubierto la pelvis y la pierna derecha; este es el modelo que hemos explicado anteriormente y que responde a la obra napolitana del siglo XVII, conservado en la Academia de San Fernando de Madrid.

A este tipo pertenecen:

San Pedro de Orazo ${ }^{74}$ (A Estrada, PonteVEdRA). AÑo: 1797

Conserva una Inscripción en el pie de la macolla: "Ref (randa) da siendo cura el LC licenciado don Ramón

Valenzuela". Es una cruz muy limpia y elegante. Existen ciertas variaciones con respecto al modelo de Bonaval: los remates trilobulados de los brazos son más elaborados y se colocan formas de rocalla finamente trabajadas, que terminan en el centro con una flor de lis, aunque se siguen colocando cálices de flor exentos al final. El Cristo conserva el halo situado en el cuadrón y en su centro se coloca una flor; en el reverso aparece San Pedro. Desde los ángulos de los brazos parten rayos dorados.

La macolla es similar a San Xoan de Lousame, pero de menor calidad y con mucha decoración. El nudo es un toro muy desarrollado, con decoración vegetal y roleos, en medio de los cuales se colocan cabezas de ángeles, muy menudas y con poco relieve. Por medio de dos cuellos (también decorados) se pasa a un bocel, en cada extremo, que se decoran con hojas grabadas.

Para compararla con otras piezas de Pecul, guarda gran parecido con la cruz de San Juan de Fecha y también con otros ejemplos como San Cristovo de Eixo, San Tirso de Mabegondo y Santa María de Turces.

\footnotetext{
${ }_{74}$ Inventario de Bienes Muebles de la Iglesia Católica, Archivo Histórico Diocesano de Santiago de Compostelano (en adelante AHDS), IIC 928.
} 
Santa María de Cosoirado ${ }^{75}$ (Moraña, PonteveDRA). AÑo: 1813

La forma trilobulada en este caso se decora con rocalla menos marcada. El molde del Cristo también concuerda con el tipo establecido por este modelo, con un halo en la zona del cuadrón y una flor en el centro del "sol".

En el reverso se coloca una asunción del estilo que podemos ver en muchas cruces de Pecul, como en Santa María de Turces: la Virgen entre nubes con una rodilla hincada y una mano en el pecho.

La macolla también adquiere una forma ya conocida en las piezas del orfebre, como por ejemplo en las cruces de Santa María de Alba o San Xoan de Toro. Comienza por un estrecho bocel que conecta con la cruz, decorado con pequeñas hojas de acanto; se pasa a un cuello con ornamentación vegetal que se divide en cuarteles verticalmente. El nudo se forma por medio de un gran toro decorado con hojas, flores y roleos, que lo parten en tres sectores, colocando una cabeza de ángel dorada en la separación. Se pasa a un cuello, sin marcar la transición, solo diferenciado por medio de la ornamentación, que ahora se realiza a base de hojas de acanto, y un bocel con gallones muy finos. En la macolla se conserva la inscripción: "SOL DE SANTA MARÍADE / COSOIRADO AÑO 1813".

Para finalizar el amarre de la vara se decora con hojas de acanto grabadas en ambos extremos.

Santiago de TaL ${ }^{76}$ (Muros, A Coruña) AÑo: 1812

Los cambios que se dan con la cruz de Santo Domingo de Bonaval son mínimos, lo único que difiere es la macolla y el reverso de la cruz, en la cual se suele disponer el patrón de la parroquia que encarga la pieza. En esta pieza no se conserva

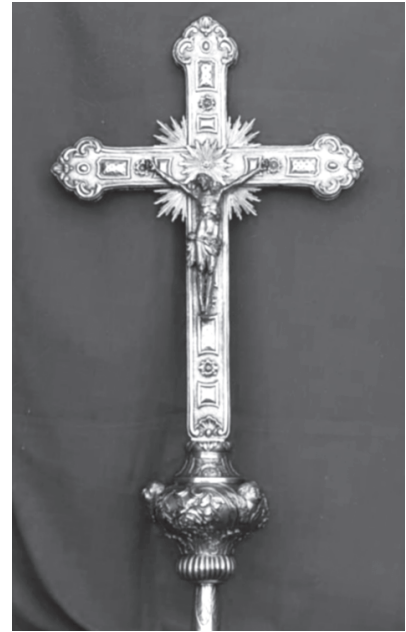

Cruz de Santa María de Cosoirado Imagen propiedad de la Consellería de Cultura, Educación e O. U. da Xunta de Galicia, Inventario de Bienes Muebles de la Iglesia Católica. Arquivo Gráfico do Museo de Pontevedra.

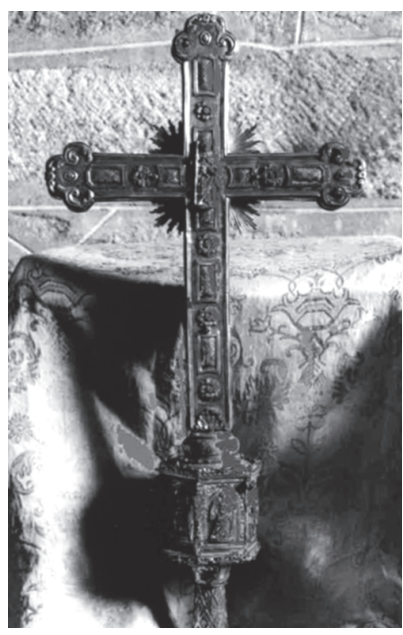

Cruz de Santiago de Tal Imagen propiedad de la Consellería de Cultura, Educación e O. U. da Xunta de Galicia, Inventario de Bienes Muebles de la Iglesia Católica.

\footnotetext{
${ }_{75}$ Inventario de Bienes Muebles de la Iglesia Católica, AHDS, IIC 35.

${ }^{76}$ Inventario de Bienes Muebles de la Iglesia Católica, AHDS, IIC 624.
} 


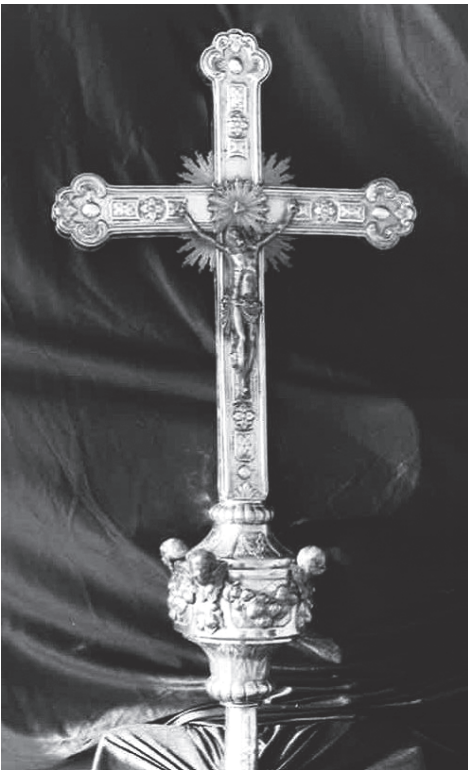

Cruz de San Pedro de Santa Comba Imagen propiedad de la Consellería de Cultura, Educación e O. U. da Xunta de Galicia, Inventario de Bienes Muebles de la Iglesia Católica. el halo de rayos que acompaña al crucificado, por lo que la zona del cuadrón queda incompleta.

En el reverso aparece el apóstol Santiago vestido de peregrino, con el bastón y casulla con vieiras. La figura flexiona la pierna derecha, dejando entrever su anatomía a través de las vestiduras. Desde el encuentro de los brazos salen rayos dorados; las figuras de Cristo y el apóstol también se realizan en plata dorada.

Se puede afirmar que la macolla no pertenece a Pecul: tiene forma hexagonal, cobija figuras bajo arcos de medio punto, con decoración rallada y vegetal calada.

Pedro de Santa Comba ${ }^{77}$ (Santa Comba, A CoRuña) AÑo: 1816

Los brazos trilobulados están, en este caso, más simplificados que los otros modelos, la forma y decoración de la cruz repite

lo descrito con anterioridad. Esta pieza conserva el halo de Cristo y, en el centro, en lugar de la flor típica, encontramos el símbolo de la trinidad. En el reverso se coloca a San Pedro, portando las llaves en la mano derecha, su postura repite la del Santiago Apóstol del ejemplo anterior.

La macolla no concuerda con sus modelos más conocidos, periforme invertida, en este caso el nudo adquiere una forma de tambor, dividido en cuarteles, cuya superficie, sin embargo, sí que utiliza motivos decorativos típicos en Pecul, con una maya romboidal y guirnaldas de flores "sujetas" por cabezas de angelitos. Se une a la cruz y a la vara por dos molduras en talud y dos boceles gallonados, uno en cada extremo.

San Andrés de Vea ${ }^{78}$ (A Estrada, Pontevedra) AÑo: 1816

El remate trilobulado de los brazos, que varía ligeramente en cada caso, es prácticamente una copia idéntica a la cruz de Bonaval: formas de rocalla y "ces" con roleos que cobijan en el centro un pequeño óvalo.

\footnotetext{
77 Inventario de Bienes Muebles de la Iglesia Católica, AHDS, IIC 763.

${ }^{78}$ Inventario de Bienes Muebles de la Iglesia Católica, AHDS, IIC 153.
} 
El molde del Cristo también es el mismo, aunque aquí su anatomía aparece un poco difuminada, no está tan bien definida como en casos anteriores. En el reverso aparece San Andrés en la postura ateriormente descrita.

La macolla sí se diferencia del ejemplo de Bonaval, deja de tener forma redondeada decorada con motivos floridos para pasar a formas más rectas, del tipo que se observa en la cruz de Santa Comba. Sigue el mismo patrón en ambos extremos, comienza con un bocel gallonado entre dos cuellos (el inferior más alargado) y el nudo con forma de tambor, decorado en su superficie por una red de rombos, guirnaldas de rosas y cabezas de querubines. Los cuellos también se decoran a base de hojas y flores.

Resulta casi idéntica a la cruz de Santa María de Leira, y también tiene paralelismos con otras piezas del orfebre como San Estevo de Paradela o San Andrés de Mobre entre otros.

Santo Tomé de Ínsua ${ }^{79}$ (VIla de CRuces, PonteVEDRA) AÑO: 1798

La anatomía de Cristo está muy difusa y ha perdido el halo de "sol" situado en la zona del cuadrón. En el reverso se encuentra la imagen de Santo Tomé.

La macolla también repite formas antes anunciadas, colocando boceles bulbosos y gallonados en los extremos, con el inferior más estilizado y decorados con motivos vegetales. El nudo se marca por tres cuarteles enmarcados en rectángulos incisos, con decoración de rosas y hojas, separados por cabezas de querubines.

A continuación se describen dos cruces que pertenecen a la tipología dada por la cruz de San Xoan de Lousame (1789).

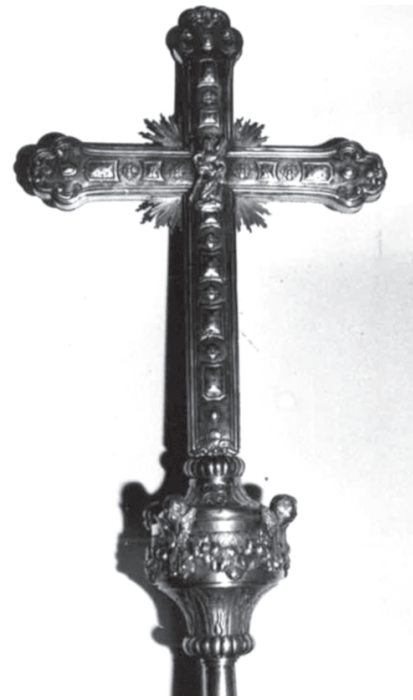

Cruz de San Andrés de Vea Imagen propiedad de la Consellería de Cultura, Educación e O. U. da Xunta de Galicia, Inventario de Bienes Muebles de la Iglesia Católica.

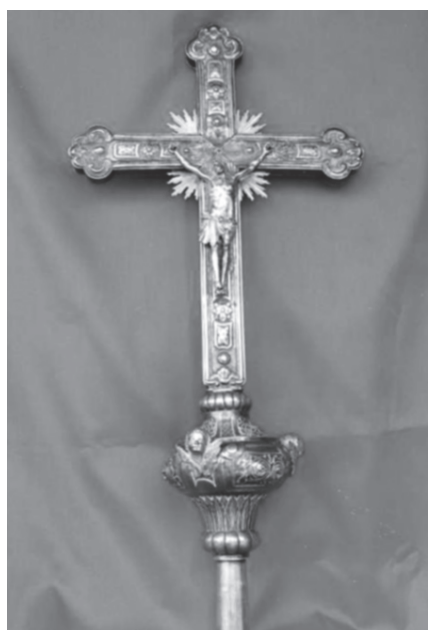

Cruz de San Tomé de Ínsua Imagen propiedad de la Consellería de Cultura, Educación e O. U. da Xunta de Galicia, Inventario de Bienes Muebles de la Iglesia Católica. Arquivo Gráfico do Museo de Pontevedra.

\footnotetext{
${ }^{79}$ Inventario de Bienes Muebles de la Iglesia Católica, AHDS, IIC 347-347.2.
} 


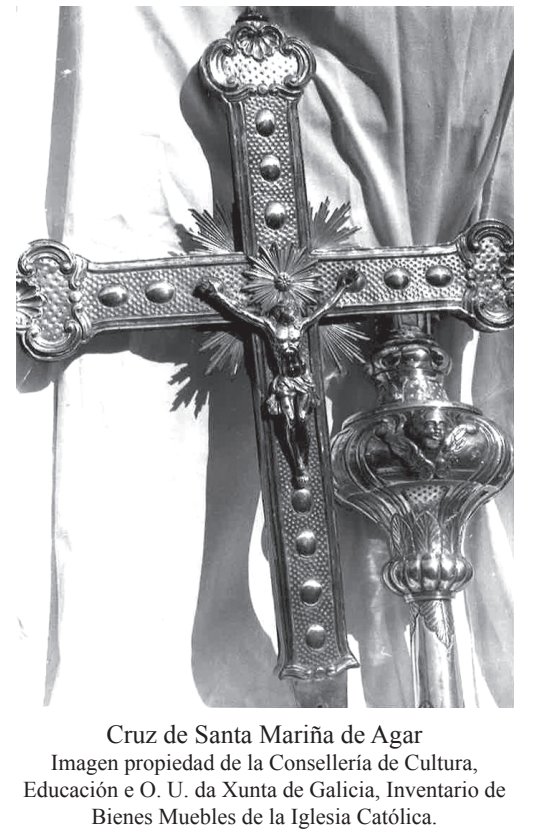

Santa Mariña de $\operatorname{Agar}^{80}$ (A Estrada, PonTEVEDRA) AÑo: 1791

Pertenece a otro de los modelos típicos de Pecul, el cual toma como referencia piezas de Simón Rodríguez ${ }^{81}$. Es una cruz latina, los brazos finalizan trilobulados y este remate se separa a través de unas bajas molduras curvas, que se juntan en un pequeño rombo. La curva trilobulada se hace a base de una "C" a cada lado y una venera gallonada en el extremo, como remate en cada brazo se coloca una pieza exenta que adquiere la forma de cáliz de flor. Toda la superficie de los brazos se puntea y se adorna con una línea de óvalos en resalte y lisos.

El crucificado responde al modelo que vemos en el Cristo de la Cruz de San Xoán de Lousame, es más pequeño que los que vemos en los ejemplos mencionados ante-

riormente, ladea la cabeza a la izquierda al tiempo que la inclina hacia atrás; el paño de pureza se anuda al frente y cuelga a ambos lados. Se elimina el cuadrón y su lugar se ocupa por el halo a base de rayos apostado detrás de la cabeza de Cristo. Rayos dorados sobresalen de la intersección de los brazos.

La macolla es periforme, del tipo usado en la cruz de San Xoán de Lousame, divide su cuerpo en tres partes bien diferenciadas, unidas a la cruz y al vástago por boceles gallonados; en la parte baja del nudo se graban motivos de hojas y se puntea la superficie. En la parte abultada se colocan cabezas de ángeles. A través de un cuello se pasa a un bocel, también punteado, que une la macolla a la cruz.

\section{Santa María de Armenteira ${ }^{82}$ (Meis, Pontevedra) AÑo: 1790}

Esta pieza guarda gran parecido con el ejemplo de Santa Mariña de Agar, por lo que repite, en cierta medida, el modelo de Simón Rodríguez, aunque es menos delicada, con una decoración más profusa.

Una cruz latina con los remates de los brazos trilobulados y adornados a base de óvalos espejo, pero esta vez decora la superficie rodeando estos medallones

\footnotetext{
${ }^{80}$ Inventario de Bienes Muebles de la Iglesia Católica, AHDS, IIC 666.

81 José Manuel López VÁzquez, “Juegos de Plateros compostelanos...”, págs. 347-360.

${ }^{82}$ Inventario de Bienes Muebles de la Iglesia Católica, AHDS, IIC 98.
} 
con pequeñas incisiones alargadas, simulando pequeñas hojas. Los brazos se rematan con un cáliz de flor exento.

En el cuadrón se coloca el halo de Cristo, dorado, cuyo molde es el mismo que el de Santa Mariña de Agar, con la cabeza girada a la izquierda y el paño anudado al frente. El halo a base de rayos situado en el cuadrón acoge en el centro una flor. En el reverso tenemos el grupo de San Bernardo con la Virgen de la leche, en plata sobredorada. El santo se postra ante María y el niño, situados a un nivel superior, y coloca una cuadrícula a modo de suelo en un intento de crear profundidad.

La macolla posiblemente se corresponda con otro momento, el color de la plata difiere bastante y la forma de pera se distorsiona, más bien parece conformarse por un toro de gran tamaño con decoración vegetal, que sería el nudo, y dos boceles, uno superior que conecta con la cruz y otro inferior de mayor tamaño para la vara, ambos geminados.

La macolla es similar a la de Sergude, un poco achaparrada, comienza con un bocel decorado por veneras y el nudo tiene forma bulbosa, ornamentado por hojas, rocalla y cabezas de angelitos.

\section{Cálices}

Santa María de Tourón ${ }^{83}$ (Ponte Caldelas, PonTEVEDRA) AÑo: 1795

Un ejemplo de cáliz, sin un juego de molduras muy acusado, pero profusamente decorado a base de relieves bastante planos, que reproducen símbolos eucarísticos y vegetales cubriendo la base, el astil y la mitad de la copa.

El pie, muy similar al ejemplo de San Pedro de Carcacia (Padrón), arranca desde una fina pestaña,

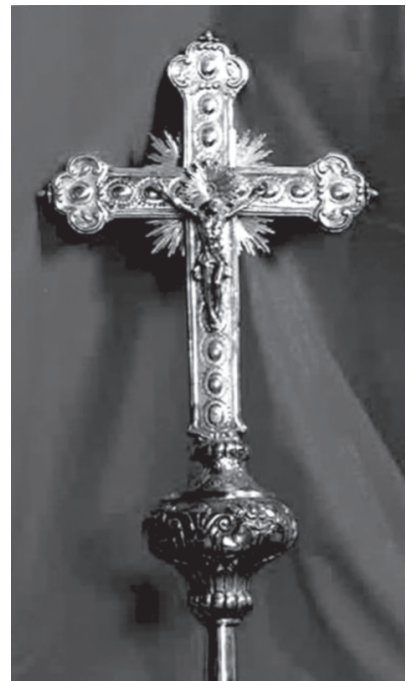

Cruz de Santa María de Armenteira Imagen propiedad de la Consellería de Cultura, Educación e O. U. da Xunta de Galicia, Inventario de Bienes Muebles de la Iglesia Católica.

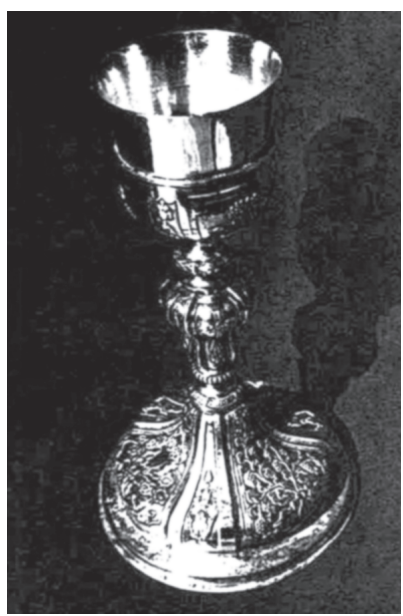

Cáliz de Santa María de Tourón Imagen propiedad de la Consellería de Cultura, Educación e O. U. da Xunta de Galicia, Inventario de Bienes Muebles de la Iglesia Católica.

\footnotetext{
${ }^{83}$ Inventario de Bienes Muebles de la Iglesia Católica, AHDS, IIC 225.
} 


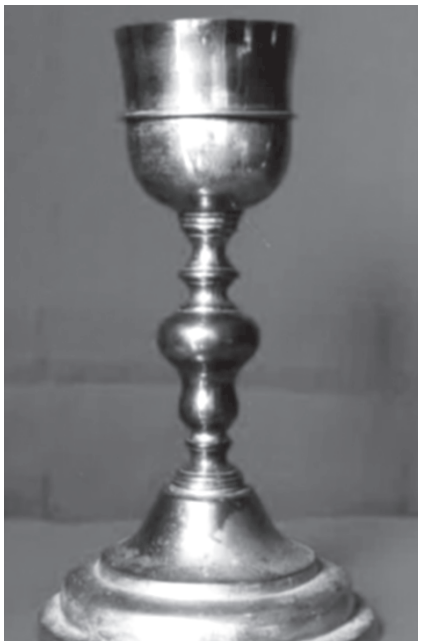

Cáliz de San Miguel de Deiro Imagen propiedad de la Consellería de Cultura, Educación e O. U. da Xunta de Galicia, Inventario de Bienes Muebles de la Iglesia Católica.

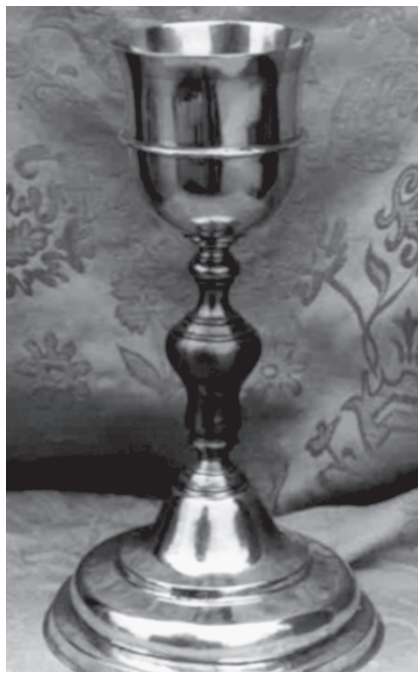

Cáliz de San Pedro de Benza Imagen propiedad de la Consellería de Cultura, Educación e O. U. da Xunta de Galicia, Inventario de Bienes Muebles de la Iglesia Católica. se pasa a un bocel, el cual se une mediante un juego sinuoso a un cuerpo ligeramente troncocónico; no existe separación entre ambos cuerpos, ni siquiera en la decoración que se adapta a la curva. Se divide verticalmente en cuatro cuarteles separados por ristras de hojas.

El astil arranca de un pequeño listel, seguido de un cuello, un nudo periforme invertido y termina con un bocel entre dos cuellos. La copa campaniforme está subdivida, la parte superior permanece lisa mientras que la inferior recibe ornamentación de vides y espigas de trigo.

San Miguel de Deiro ${ }^{84}$ (Vilanova de Arousa, Pontevedra) AÑo: 1798

La base se escalona en tres molduras: dos pestañas aristadas y entre ellas un semitoro. Sobre la pestaña superior se levanta un cuerpo troncocónico desde el que arranca un astil, con un bocel estriado, un cuello y de nuevo un bocel. El nudo adopta la forma periforme invertida, bastante estilizado y estrangulado en su centro; el astil se remata con un nuevo bocel entre dos cuellos y se une a la copa por un cuarto de toro estriado. La copa es prácticamente cilíndrica y se subdivide por un plato.

Para compararla con otras piezas de Pecul podemos acudir a los ejemplos de Santa María de Arzúa o San Cristobo de Enfesta.

San Pedro de Benza ${ }^{85}$ (Trazo, A Coruña) Año: 1800

El pie repite la forma de la mayoría de los cálices de Pecul, formado por dos pestañas aristadas, la inferior más desarrollada en altura, que enmarcan un semitoro. Sobre la tercera moldura

\footnotetext{
${ }^{84}$ Inventario de Bienes Muebles de la Iglesia Católica, AHDS, IIC 846.

${ }^{85}$ Inventario de Bienes Muebles de la Iglesia Católica, AHDS, IIC 1692.
} 
arranca un cuerpo troncopiramidal, bastante desarrollado en altura que termina en unas finas incisiones a modo de baquetones.

El astil nace de un cuello corto y estrangulado que da paso a un bocel que casi no se separa del nudo periforme, pero ligeramente deformado a medida que se estiliza, la parte superior del nudo se decora en su término con dos listeles muy finos. A continuación se pasa a un cuello también estilizado, un bocel bastante desarrollado pero un poco achaparrado, y finalmente un juego de baquetones sobre los que se asienta la copa, levemente campaniforme, con los bordes dorados y subdivida por un plato.

Se pueden establecer parecidos con otros cálices atribuidos a Pecul: San Cristóbal de Dombodán o Santa María de Turces entre otros.

San Andrés de VeA ${ }^{86}$ (A Estrada, PonteveDRA) AÑO: 1800

Este ejemplo es una amalgama de dos cálices similares; el astil y la copa, responden a las formas de San Pedro de Carcacia (Padrón), mientras que la base es muy similar al cáliz de Santiago de Padrón.

El pie se conforma por tres molduras: dos pestañas y entre ambas un toro convexo. Parte de una pestaña decorada en su arista con punteado, pasa al toro convexo, inciso en tres cuarteles rectangulares rehundidos con los ángulos en chaflán, estos se alternan con otros sectores cuadrados, también con ángulos achaflanados. Los primeros cobijan guirnaldas de flores y los segundos una sola roseta. Desde el toro se pasa a la segunda pestaña, muy reducida en diámetro y altura, decorada con punteado; desde ella parte un

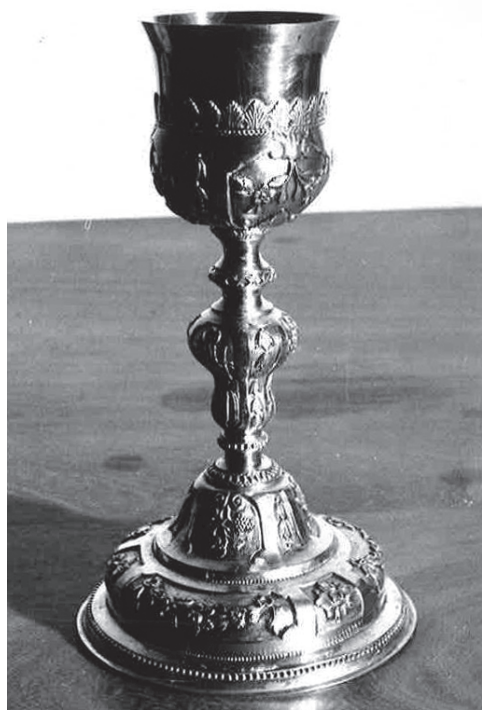

Cáliz de San Andrés de Vea Imagen propiedad de la Consellería de Cultura, Educación e O. U. da Xunta de Galicia, Inventario de Bienes Muebles de la Iglesia Católica. tronco piramidal, que se ornamenta de nuevo a base de cuarteles rehundidos con decoración eucarística: racimos de uvas y espigas acompañadas de ristras de hojas. Se remata con una moldura baja y punteada.

Desde esta moldura se pasa al astil por medio de un cilindro, sobre este un bocel también punteado; después al nudo periforme, muy estrangulado en su centro, el cual recibe la misma decoración que la base, con ristras de hojas

\footnotetext{
${ }^{86}$ Inventario de Bienes Muebles de la Iglesia Católica, AHDS, IIC 152.
} 


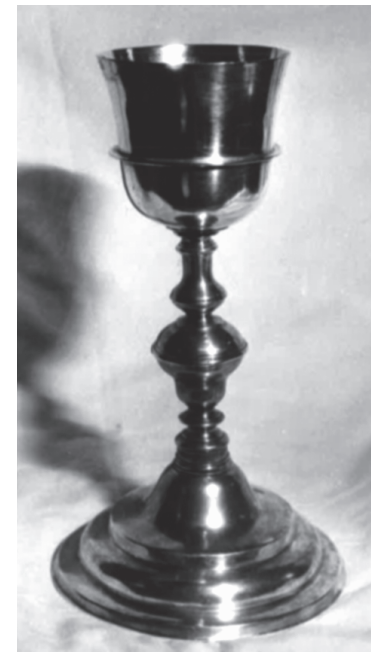

Cáliz de San Xiao de Vea Imagen propiedad de la Consellería de Cultura, Educación e O. U. da Xunta de Galicia, Inventario de Bienes Muebles de la Iglesia Católica.

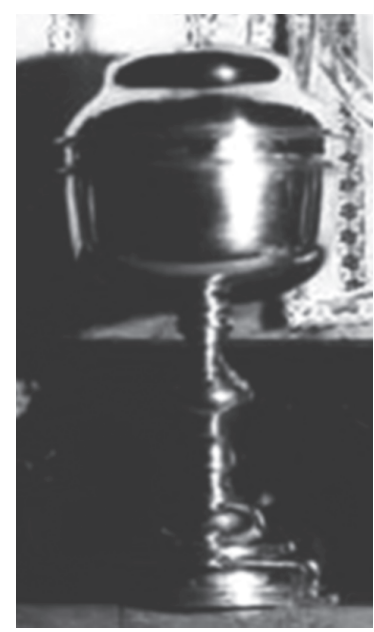

Copón de San Julián de Malpica Imagen propiedad de la Consellería de Cultura, Educación e O. U. da Xunta de Galicia, Inventario de Bienes Muebles de la Iglesia Católica. recorriéndolo en sentido vertical. Tiene un remate simétrico compuesto por un toro entre dos cuellos.

La copa, campaniforme, se subdividide por la decoración, en la parte inferior repite los sectores geométricos rehundidos, esta vez trapezoidales, donde se colocan rosas y hojas. En lugar del plato se coloca un rosario de hojas cortas que rodean la copa.

San Xiao de $\operatorname{VeA}^{87}$ (A Estrada, Pontevedra)Año: 1811

Es una pieza muy sinuosa, con profusión de formas cóncavas y convexas. La base se divide en tres molduras bien diferenciadas: una pestaña aristada da paso a un semitoro poco desarrollado en altura y a otra pestaña. Desde la base de esta última moldura se levanta un cuerpo troncopiramidal, que crece bastante en altura para acabar bruscamente en un bocel y un balaustre o plato. A continuación está el nudo, con forma de pera invertida, la parte superior se divide por un listel; para terminar, un cuello da paso a un bocel bulboso, dividido por otro listel, desde el que parte un cilindro rematado por un juego de baquetones en el que se asienta la copa, esta es campaniforme y se divide por un plato.

Se pueden ver similitudes con el cáliz de San Pedro de Beado, en la Capilla de San Ramón, (Boiro).

\section{Copones}

San Julián de Malpica ${ }^{88}$ (Malpica, A Coruña) AÑo: 1799

También similar a Santa María de Argalo; la base se levanta sobre una moldura rectangular muy desarrollada en altura, se pasa a un semitoro desde el que parte un cuerpo troncopiramidal que se remata por unos baquetones que dan paso a un cuello. El astil

\footnotetext{
${ }^{87}$ Inventario de Bienes Muebles de la Iglesia Católica, AHDS, IIC 884.

${ }^{88}$ Inventario de Bienes Muebles de la Iglesia Católica, AHDS, IIC 482.
} 
se forma a base de un nudo periforme, invertido y liso, que conecta con un cuello moldurado con finos listeles, finalizando en un bocel que da paso a la copa.

La copa es de sección circular y se divide por un plato cerca del borde. La tapa en este caso no sigue el juego de la base, como veremos en otros ejemplos, si no que la forman dos cuerpos unidos por una curva sinuosa.

\section{Santiago de Vilamaior ${ }^{89}$ (Ordenes, A Coruña)} AÑo: 1808

Presenta una base muy desarrollada, destacando entre todos los ejemplos conocidos. Arranca de una alta moldura plana sobre la que se levantan tres pestañas, mucho más bajas y escalonadas en diámetro. De la última parte un cuerpo troncopiramidal que corta bruscamente su crecimiento y pasa, sin mucha fluidez, a un bocel bulboso seguido de un cuello antes de encontrarse con el nudo; este no tiene la forma de pera acostumbrada hasta el momento, sino de una gota lisa. Desde el nudo nace un cuello largo y estilizado que se frena en un estrecho bocel.

La copa es de sección circular y lisa. La tapa se divide en dos partes: la primera recta, que sigue el cuerpo de la copa, y un remate de sección sinuosa que va creciendo en altura para acabar en una cruz de brazos iguales que se ensanchan desde el centro.

\section{Santa María de Cuntis ${ }^{90}$ (Cuntis, Pontevedra)} AÑo: 1809

Su pie, poco desarrollado, se forma a base de dos molduras: la primera es una pestaña aristada y la superior de perfil semi-convexo, que da paso, sinuosamente, a un cuerpo troncocónico desde el

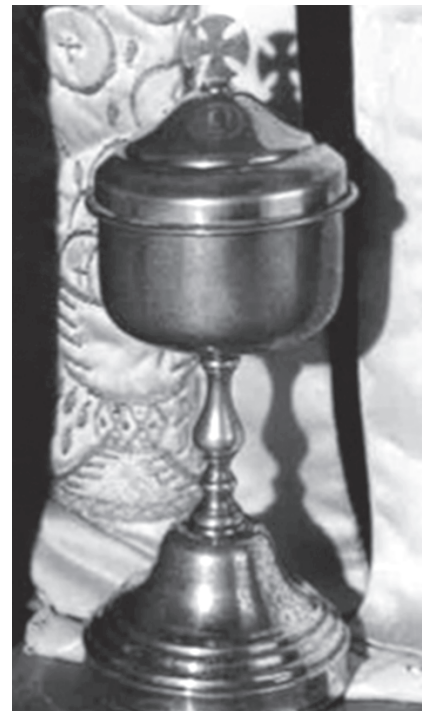

Copón de Santiago de Vilamaior Imagen propiedad de la Consellería de Cultura, Educación e O. U. da Xunta de Galicia, Inventario de Bienes Muebles de la Iglesia Católica.

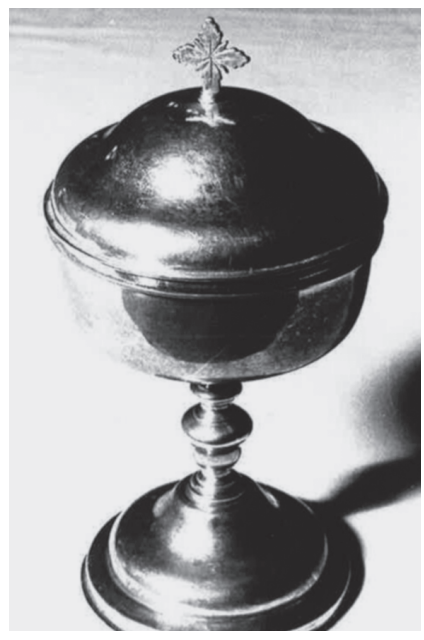

Copón de Santa María de Cuntis Imagen propiedad de la Consellería de Cultura, Educación e O. U. da Xunta de Galicia, Inventario de Bienes Muebles de la Iglesia Católica.

\footnotetext{
${ }^{89}$ Inventario de Bienes Muebles de la Iglesia Católica, AHDS, IIC 2028.

${ }^{90}$ Inventario de Bienes Muebles de la Iglesia Católica, AHDS, IIC 339.
} 
que parte el astil, apoyado en unos baquetones. Consta de un nudo periforme, un cuello y un bocel.

La copa de sección circular, con una tapa muy simple y lisa, sin moldurar, solo se ornamenta con el juego cóncavo-convexo que provoca el paso de los dos cuerpos que la forman. Se corona con una cruz griega adornada con rayos que salen de los ángulos de los brazos.

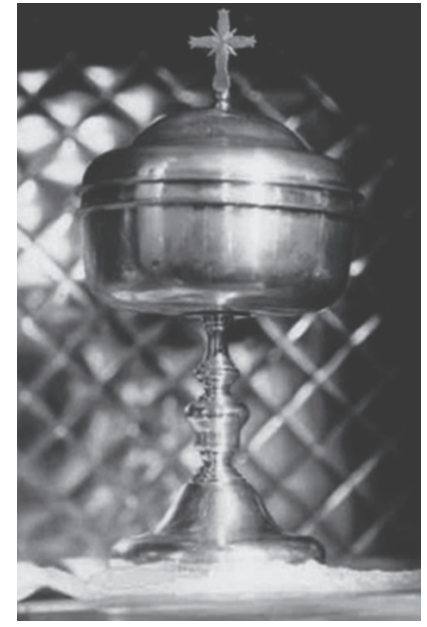

Copón de San Martín de Andeiro Imagen propiedad de la Consellería de Cultura, Educación e O. U. da Xunta de Galicia, Inventario de Bienes Muebles de la Iglesia Católica.

San Martín de Andeiro91 (Cambre, A Coruña) AÑo: 1810

Cuenta con un pie, como el ejemplo anterior, muy poco desarrollado; con dos cuerpos, el primero se forma por un semitoro, que se levanta en su base para formar el segundo, troncocónico, el cual se remata por una serie de baquetones escalonados en altura, creando un estrangulamiento. A continuación se pasa a otra serie de baquetones sobre los que se asienta el nudo periforme, ligeramente achaparrado y liso; desde éste un cuello antecede a un bocel, dividido horizontalmente por un listel y por último un cilindro muy estrecho sobre el que se levanta la copa, que es de sección circular, dividida con un plato cerca del borde.

La tapa es lisa, repite en cierta medida el juego de cuerpos en transición, convexo-cóncavo, que se ve en la base. Se remata por una cruz latina con rayos que nacen desde los ángulos.

Resulta muy similar al copón de Santa María de Argalo, sin contar con la cruz.

\section{Incensarios}

San Xiao de Vea (A Estrada, A Coruña) Año: $1811^{92}$

El cuerpo del humo adquiere una forma ligeramente periforme, casi esférica, y un poco achaparrada. Se puede dividir horizontalmente en tres partes. La parte inferior actúa de cierre, como una moldura lisa en talud y aristada, que une el cuerpo con la casca.

\footnotetext{
${ }^{91}$ Inventario de Bienes Muebles de la Iglesia Católica, AHDS, IIC 1718.

${ }^{92}$ Inventario de Bienes Muebles de la Iglesia Católica, AHDS, IIC 881.
} 
La parte central aparece muy calada, se estructura verticalmente en tres cuarteles, separados por grandes hojas de acanto recortadas que ejercen de cubrecadenas y también ocultan los nervios estructurales. Los cuarteles presentan una profusa decoración vegetal: en el centro óvalos flanqueados por molduras en forma de "ces". Se cierra con un anillo liso sobre el que se levanta un remate semiesférico calado, formado por hojas de acanto cuyas puntas arrancan del anillo, y se unen en el centro, sujetando la argolla de la cadena que conecta con el manípulo; este es circular y comparte la decoración a base de hojas de acanto, esta vez grabadas.

La casca repite la forma de pera, también casi semiesférica, pero ahora invertida; en cierta medida copia la estructura del cuerpo del humo: se divide verticalmente con tres hojas de acanto creando cuarteles, que en este caso no se horadan, y se enmarcan en resaltos trapezoidales dentro de los cuales se coloca decoración vegetal.

La base es muy sencilla, se une al conjunto por un cuello bajo que conecta con un cuarto de bocel, para asentarse en una pestaña bastante desarrollada.

Responde a los modelos de los incensarios de Santa María de Alba, Santa María de Castelo o al de Santa María de Toxosouto.

San Miguel de Deiro ${ }^{93}$ (Vilanova de Arousa, Pontevedra) AÑo: 1811

Resulta más desarrollado y estilizado que los ejemplos anteriores. El cuerpo del humo es periforme y más calado. Se divide en tres partes verticalmente, los nervios por donde van las cadenas vuelven a cubrirse con hojas de acanto recortadas. Los cuarteles, que adquieren una forma trapezoidal, se calan casi por completo configurando una ornamentación vegetal, que enmarca en cada sector un óvalo flanqueado por "ces".

\footnotetext{
93 Inventario de Bienes Muebles de la Iglesia Católica,
} AHDS, IIC 830.
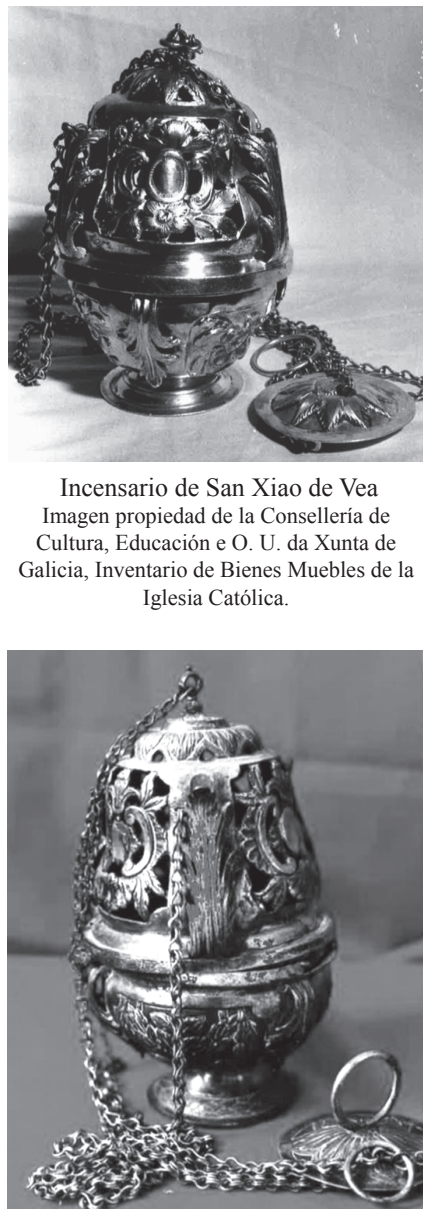

Incensario de San Miguel de Deiro Imagen propiedad de la Consellería de Cultura, Educación e O. U. da Xunta de Galicia, Inventario de Bienes Muebles de la Iglesia Católica. 
La parte inferior se forma por una moldura aristada y lisa que hace de tapa con la casca. La parte superior parte de un anillo liso y sobre este se colocan hojas de acanto, mucho menos desarrolladas, que sirven de base a una pequeña pestaña circular en la que se ancla la argolla de la cadena que engancha el manípulo, este es circular, mucho más plano que los ejemplos anteriores, y repite la decoración gravada a base de hojas de acanto.

La casca, con forma semiesférica, imita la estructura del cuerpo anterior pero sin calar la superficie. Se divide en cuarteles trapezoidales con decoración vegetal, separados por hojas de acanto recortadas, exentas en ciertas zonas.

El pie resulta muy sencillo y pequeño: un cuarto de bocel une el conjunto con una estrecha pestaña.

\section{San Andrés de VeA ${ }^{94}$ (A Estrada, Pontevedra) AÑo: 1815}

El cuerpo del humo, cómo en los ejemplos anteriores, es periforme pero algo achaparrado, dándole un ligero aspecto semiesférico. Se cierra en la base con la casca por medio de una moldura en talud lisa. Se divide en tres cuarteles separados por tres hojas de acanto recortadas que actúan de cubrecadenas. Los cuarteles se ocupan por un marco trapezoidal, cuyo interior se cala con hojas de acanto, y en el centro pequeños vanos también de forma trapezoidal, con decoración de "ces" a ambos lados.

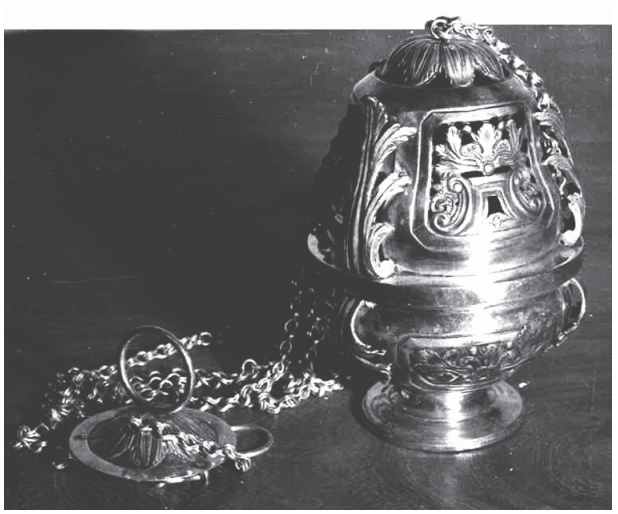

Incensario de San Andrés de Vea Imagen propiedad de la Consellería de Cultura, Educación e O. U. da Xunta de Galicia, Inventario de Bienes Muebles de la Iglesia Católica.

Un anillo en la parte superior sirve de arranque del remate formado por hojas de acanto, que unen sus bases para hacer de soporte a la argolla de la cadena. El manípulo es circular, formado por una pestaña plana y un ligero resalte semiesférico con hojas de acanto imitando el remate del cuerpo del humo.

La casca imita la división del cuerpo superior, pero sin calar, y la base es sencilla sin decorar, formada por una pestaña aristada unida al conjunto por un cuello.

\footnotetext{
${ }^{94}$ Inventario de Bienes Muebles de la Iglesia Católica, AHDS, IIC 157.
} 


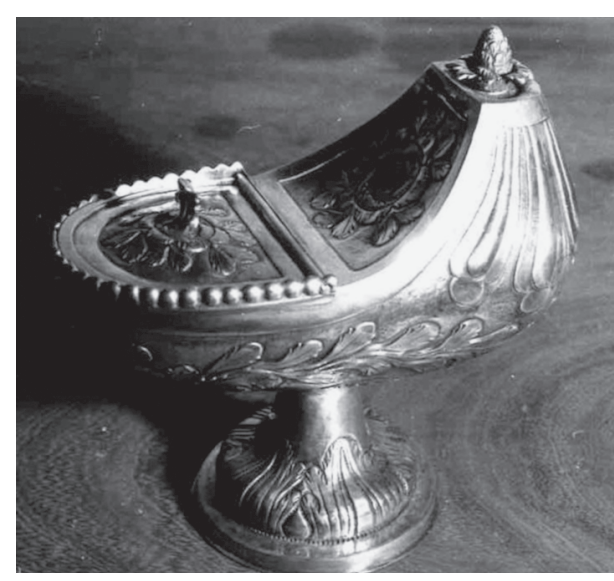

Naveta de San Andrés de Vea

Imagen propiedad de la Consellería de Cultura, Educación e O. U. da Xunta de Galicia, Inventario de Bienes Muebles de la Iglesia Católica.

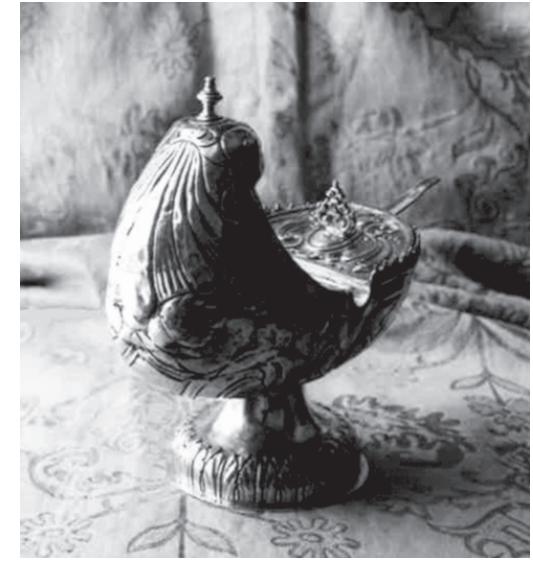

Naveta de Santa María do Campo

Imagen propiedad de la Consellería de Cultura, Educación e O. U. da Xunta de Galicia, Inventario de Bienes Muebles de la Iglesia Católica.

\section{Navetas}

San Andrés de Vea ${ }^{95}$ (A Estrada, Pontevedra) AÑo: 1815

Muy ornamentada a base de relieves muy planos, pero el conjunto resulta muy fino y elegante. El pie es muy sencillo, una moldura aristada sobre la que parte un toro con la base punteada y cubierta por hojas de acanto, las cuales se fusionan, sin mostrar transición, con un cuello estilizado.

La quilla elíptica se decora por toda la superficie por hojas y rosas, y la zona de la tapa se bordea con perlas; no se marca la separación entre esta y el mascarón, el cual se cubre con una venera gallonada y el tope recto se corona con un cáliz de flor. En la tapa se coloca el motivo de una rosa en cuyo centro se levanta un tirador plano. La proa se yergue y se decora en el interior con flores.

Responde al ejemplo más típico de las navetas de Pecul, un ejemplo similar puede ser San Esteban de Piadela.

\section{Santa María do CAmpo ${ }^{96}$ (A Coruña) AÑo: 1816}

Más o menos responde a la estructura sistematizada por la naveta de Santa María de Alba. La base se forma por una pestaña muy plana desde la que arranca un toro, adornado en todo su contorno por finas hojas de acanto y que se une a la nave por medio de un estilizado cuello.

\footnotetext{
${ }^{95}$ Inventario de Bienes Muebles de la Iglesia Católica, AHDS, IIC 155.

${ }^{96}$ Inventario de Bienes Muebles de la Iglesia Católica, AHDS, IIC 732.
} 
La quilla es elíptica ornamentada por medio de elementos vegetales: hojas y flores. Se remata en la zona de la tapa con un abalaustramiento plano, conformado por pequeñas hojas de acanto; la tapa también recibe ornamentación y un tirador plano. El paso entre el mascarón y la quilla solo se evidencia por la decoración, este se decora por medio de una venera gallonada rodeada por hojas; el mascarón se corona con un remate con forma de "peón", que viene a sustituir al cáliz de flor que aparece en otros ejemplos ya conocidos, como puede ser la naveta de Santa María de Arzúa.

Es similar a la naveta de Santa Uxía de Faro o a la de Santa María de Abade. Lo que puede disentir es el borde, que en los ejemplos ya documentados se realiza siempre a partir de perlas, y aquí lo hace con una especie de balaustrada.

\section{Ostensorios}

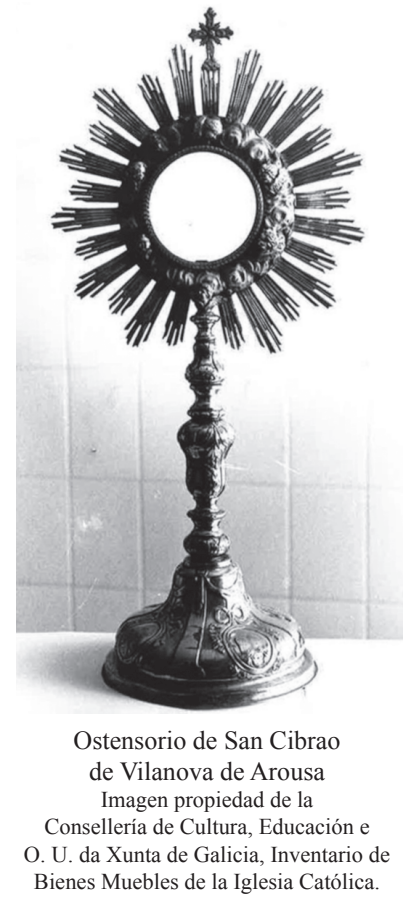

San Cibrao de Vilanova de Arousa ${ }^{97}$ (Vilanova de Arousa, Pontevedra) AÑo: 1792

A pesar de que en el Libro de Caja solo aparece como encargo un viril, el astil también puede atribuirse, puesto que es muy similar a otros que se han documentado, como el viril de Dombodán y el de San Tirso de Mabegondo.

La base se levanta sobre una pestaña aristada, un toro que va creciendo y que se fusiona con un cuerpo troncocónico, generando un juego cóncavo-convexo; la diferenciación entre ambas partes se da a través de la decoración.

El pie se divide en vertical en cuatro cuarteles separados por listeles lisos. En los cuarteles se colocan medallones rodeados de ornamentación vegetal, se engarzan por medio de la representación de un lazo a una especie de paño colgante, que simula engancharse con argollas al arranque del astil.

El astil se levanta por medio de un bocel bulboso con motivos vegetales y a continuación, entre dos cuellos cortos, se coloca un segundo bocel. El nudo es periforme invertido, adornado verticalmente por ristras vegetales, un bocel estrecho perlado, un cuello

\footnotetext{
${ }^{97}$ Inventario de Bienes Muebles de la Iglesia Católica, AHDS, IIC 263.
} 
y un segundo nudo periforme más pequeño y sin invertir, de nuevo un cuello y, finalmente, un bocel estrecho en el que se apoya el viril.

El perímetro interior del sol se forma por un rosario de perlas muy menudas, se enmarca por un círculo de nubes entre las que se colocan cabezas de ángeles y de las nubes salen haces de rayos escalonados en altura. Se corona con una cruz griega.

En comparación con otros ejemplos, el viril es igual o muy parecido al de San Tirso de Mabegondo, y la vara también se parece aunque no se adorna con ángeles.

\section{Santiago de Boimorto ${ }^{98}$ (Boimorto, A Coruña)} AÑo: 1803

La base se levanta sobre una pestaña, sigue una moldura alta en talud y lisa, sobre la que se coloca un cuarto de bocel que pasa a un cuerpo troncopiramidal sin escalonar, unificado a través de la decoración; se divide en cuatro cuarteles trapezoidales, enmarcados por listeles lisos dentro de los cuales se disponen motivos vegetales. Desde este cuerpo se pasa directamente a un bocel bulboso muy desarrollado, con decoración vegetal; tras éste, otro bocel dividido por un cordón perlado y colocado entre dos cuellos. Tiene un nudo periforme bastante estilizado y decorado con ristras vegetales.

Desde el nudo parte un cuello más largo que los anteriores, sobre el que se asienta un pequeño bocel redondeado y un cuerpo cilíndrico estrecho, que también recibe elementos vegetales; se remata con un pequeño balaustre.

El viril quiere dar la sensación de que está flo-

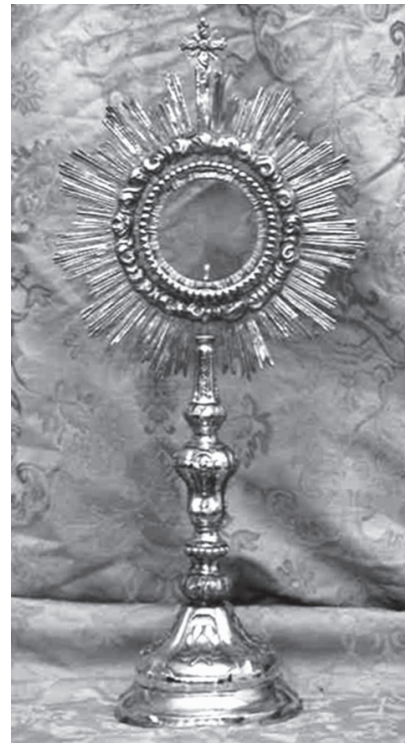

Ostensorio de Santiago de Boimorto Imagen propiedad de la Consellería de Cultura, Educación e O. U. da Xunta de Galicia, Inventario de Bienes Muebles de la Iglesia Católica. tando, etéreo, así el interior formado por un cordón de perlas, se separa del anillo de nubes, y entre ellos se ven los haces de rayos dorados que los sobrepasan y se escalonan en altura. El conjunto se corona con una cruz griega con rayos entre los ángulos.

Es muy similar al ostensorio de San Cristóbal de Dombodán y el astil se parece a San Tirso de Mabegondo exceptuando los querubines.

$$
* * *
$$

\footnotetext{
${ }_{98}$ Inventario de Bienes Muebles de la Iglesia Católica, AHDS, IIC 69.

${ }^{99}$ Las dos obra consultadas fueron, José Manuel LóPez VÁzquez, "Tipologías de la orfebrería...", págs. 91-127, y José Manuel LóPEZ VÁzQuez, “Juegos de Plateros compostelanos...”, págs. 347-360.
} 
La presente investigación se ha ceñido exclusivamente a las obras documentadas en el Libro de Caja. Sin embargo, al realizar el vaciado del Registro de Bienes Muebles de la Iglesia Católica se llega a la conclusión de que existe un número considerable de piezas atribuibles a Pecul Montenegro que no aparecen registradas en el Libro de Caja, como también ha hecho constar López Vázquez en sus publicaciones ${ }^{99}$; es por ello que aún queda obra del orfebre por localizar y estudiar, para que engrandezca y exalte el patrimonio de la platería gallega, a menudo olvidado.

Este trabajo quiere sensibilizar y concienciar sobre el valor de la obra de Pecul, como autor clave de la platería compostelana, iniciador y promotor de las formas que marcarían el neoclásico, por tanto una figura clave para entender la evolución de la orfebrería en Galicia.

Su producción, que ha llegado a prácticamente a todo el territorio gallego, ha servido para allegar los últimos posos de aquel gusto francés más elegante, que fuera tan importante en la Compostela del silgo XVIII, y al mismo tiempo para unir elementos propios de los talleres locales, en unas piezas de gran originalidad que dejarían impronta en las producciones posteriores.

El objetivo último de esta catalogación es convertirse en una herramienta útil a la hora de realizar una adecuada gestión de este patrimonio, puesto que este mobiliario litúrgico en plata está constantemente amenazado con desaparecer, ya sea por hurtos, por el mal estado de conservación debido a la dejadez, o simplemente al desconocimiento general de estas piezas, que conforman el imaginario tradicional de nuestra liturgia.

Al concluir con esta investigación se evidencia que la orfebrería en Galicia es un campo de investigación en el que se debe ahondar, cuanto más si tenemos en cuenta que la platería ha tenido un gran peso en la ciudad de Santiago de Compostela, que su producción sigue formando parte hoy en día del ceremonial religioso, y que por consiguiente su tradición sigue viva, aunque por el momento, sea en el anonimato.

\section{BIBLIOGRAFÍA}

Alcolea Gil, Santiago, Artes decorativas en la España cristiana: siglos XI-XIX, vol. 20, Ars Hispaniae, Madrid, Plus Ultra, 1975.

Balsa de la Vega, Rafael, Orfebrería gallega: notas para su historia, Madrid, Fototipia de Hauter y Menets, 1912.

Bouza Brey, Fermín, "De la fecha de nacimiento y otros datos del orfebre compostelano Francisco Pecul", Compostellanum. Revista trimestral de la archidiócesis de Santiago de Compostela. Sección de ciencias eclesiásticas, vol. 9, nº. 2 (1964). 
Couselo Bouzas, José, Galicia Artística en el siglo XVIII y primer tercio del XIX, Santiago de Compostela, Instituto Teológico Compostelano, 2005 (Collectanea Scientifica Compostellana, 18).

Larriba Leira, Mariel, "La platería religiosa del Barroco en Compostela" en Francisco Singul (ed.), Pratería e acibeche en Santiago de Compostela. Obxectos litúrxicos e devocionais para o rito sacro e a peregrinación (ss. $I X-X X$ ), Santiago de Compostela, Xunta de Galicia, 1998, pág. 229.

López Vázquez, José Manuel, “Juegos de Plateros compostelanos en el arte contemporáneo (1787-1914)", en Francisco Singul (ed.), Pratería e Acibeche en Santiago de Compostela. Obxectos litúrxicos e devocionais para o rito sacro e a peregrinación (ss. IX-XX), Santiago de Compostela, Xunta de Galicia, 1998.

López Vázquez, José Manuel, “La escultura neoclásica”, en Francisco Rodríguez Iglesias (dir.), Galicia. Arte, v. XV, A Coruña, Hércules Ediciones, [d. 1. 1993].

López Vázquez, José Manuel, “Tipologías de la orfebrería religiosa gallega”, en Rafael Taboada Vázquez (dir.), Oro, plata y piedra para la escena sagrada en Galicia: curso de orfebrería y arquitectura religiosa: La Coruña, del 2 al 11 de Mayo de 1994, A Coruña, Asociación de Amigos de la Colegiata y del Museo de arte Sacro de La Coruña, 1995.

López Vázquez, José Manuel, “Tipoloxías da ourivería” en José Manuel García Iglesias, Galicia Renace: exposición en Santiago, Iglesia de San Martín Pinario: 10 de xuño -outubro, Santiago de Compostela, Consellería de Cultura e Comunicación Social, [1997].

Singul, Francisco, "La platería y el Azabache compostelanos: una reflexión previa al estudio de sus tipologías, formas y tradiciones", en Francisco Singul (ed.), Pratería e Acibeche en Santiago de Compostela. Obxectos litúrxicos e devocionais para o rito sacro e a peregrinación (ss. IX-XX), Santiago de Compostela, Xunta de Galicia, 1998.

Vázquez Santos, Rosa, "Pratería Compostelana barroca e neoclásica. Cruces procesionais, cálices e ostensorios", en Calvo Domínguez, Marcelina (dir.), Santiago. A Esperanza, Xunta de Galicia, [d. 1. 1999].

Vila Jato, María Dolores, "Orfebrería renacentista en Santiago", en Francisco Singul (ed.), Pratería e Acibeche en Santiago de Compostela. Obxectos litúrxicos e devocionais para o rito sacro e a peregrinación (ss. IX-XX), Santiago de Compostela, Xunta de Galicia, 1998. 
